\title{
Traducción de la sentencia de la Corte Internacional de Justicia en el caso Presuntas violaciones de derechos soberanos y espacios maritimos en el mar Caribe (Nicaragua c. Colombia). Excepciones preliminares
}

\author{
Ricardo Abello Galvis", Walter Arévalo Ramírez ${ }^{*}$, \\ María Alejandra Gómez ${ }^{* * *}$, Andrés Sarmiento Lamus ${ }^{+}$ \\ y Giovanny Vega Barbosa ${ }^{++}$
}

* Profesor principal de Derecho Internacional Público de la Facultad de Derecho de la Universidad del Rosario (Bogotá, Colombia); miembro de la Corte Permanente de Arbitraje (CPA) (2014-2019); M/Phil en Derecho Internacional y Relaciones Internacionales del Instituto de Altos Estudios Internacionales de Ginebra (IUHEI); estudiante de Doctorado en Ciencias Jurídicas de la Pontificia Universidad Javeriana; director/editor del ACDI - Anuario Colombiano de Derecho Internacional; expresidente de la Academia Colombiana de Derecho Internacional (Accoldi); asociado del Instituto Hispano Luso Americano de Derecho Internacional (IHLADI). Correo electrónico: ricardo.abello@urosario.edu.co

** Profesor de Derecho Internacional Público de la Facultad de Derecho de la Universidad del Rosario (Bogotá, Colombia); LLM (Master of Laws) en Derecho Internacional; asistente de investigación de la Stetson University College of Law (2014); especialista en Derecho Constitucional, abogado y politólogo (cum laude); investigador del Grupo de Investigación de Derecho Internacional de la Facultad de Jurisprudencia de la Universidad del Rosario; estudiante de Doctorado en Derecho de la Universidad del Rosario; director de la Red Latinoamericana de Revistas de Derecho Internacional (Relaredi.org). Correo electrónico: walter.arevalo@urosario.edu.co

*** Estudiante de Jurisprudencia de la Universidad Colegio Mayor de Nuestra Señora del Rosario; miembro del Observatorio de Derecho Internacional del ACDI; pasante en la Misión de Colombia ante las Naciones Unidas en Ginebra durante el período 2015-I; asistente jurídica en la firma Cremades \& Calvo-Sotelo Abogados. Correo electrónico: malegozu@gmail.com

+ Profesor e investigador de la Universidad Sergio Arboleda en Derecho Internacional Público; candidato a Doctor (PhD candidate), Universidad de Leiden (Países Bajos); estudios avanzados de Maestría (LLM Adv.) en Derecho Internacional Público, Universidad de Leiden; miembro de la Academia Colombiana de Derecho Internacional. Correo electrónico: andres.sarmiento@usa.edu.co

++ Abogado de la Universidad del Rosario, profesor titular de la cátedra de Derecho Internacional Público de la Facultad de Jurisprudencia de la Universidad del Rosario. Correo electrónico: giovanny.vega@urosario.edu.co 
Nota: a continuación, se presenta una traducción no oficial al idioma español del texto de la sentencia de excepciones preliminares proferida por la Corte Internacional de Justicia, el 17 de marzo de 2016, en el caso Presuntas violaciones de derechos soberanos y espacios marítimos en el mar Caribe (Nicaragua c. Colombia). El texto original de la sentencia puede ser consultado en la página web de la Corte, en la siguiente dirección: http://www.icj-cij.org. La presente traducción es exclusivamente para fines de divulgación y no tiene carácter oficial. No existe una versión oficial en español de las sentencias de la Corte, estas se emiten solo en sus idiomas oficiales, los cuales son, según el artículo 39-1 del Estatuto, el francés y el inglés. Además, de acuerdo con lo ordenado en el párrafo 2 del mismo artículo, en cada sentencia la Corte determina cuál es el idioma en el cual hace fe. En el caso de la sentencia del 17 de marzo de 2016 sobre Presuntas violaciones de derechos soberanos y espacios maritimos en el mar Caribe, este idioma es el inglés. En el caso de la sentencia del 17 de marzo de 2016 sobre Cuestión de delimitación de la plataforma continental entre Nicaragua y Colombia más allá de las 200 millas náuticas desde la costa nicaragüense, este idioma es el francés. Si bien la sentencia sobre delimitación más allá de las 200 millas náuticas corresponde al caso 154 en la Lista General de la Corte, y la sentencia sobre presuntas violaciones de derechos soberanos y espacios marítimos corresponde al caso 155 en la Lista General de la Corte, este volumen del Anuario Colombiano de Derecho Internacional presenta las traducciones de las mencionadas sentencias siguiendo el orden que la Corte estableció en las audiencias orales del 17 de marzo de 2016. Por razones de espacio, no es posible incluir aquí el texto integral de las opiniones individuales y disidentes que algunos jueces decidieron añadir a cada sentencia. Sin embargo, al final de cada traducción de sentencia, se incluyó también la traducción de los resúmenes de las opiniones de los jueces, preparados por la Secretaría de la Corte. 
Cronología del procedimiento

I. Introducción

II. Primera excepción preliminar 20-48

III. Segunda excepción preliminar

IV. Tercera excepción preliminar

V. Cuarta excepción preliminar

102-104

VI. Quinta excepción preliminar

105-110

Cláusula operativa

111 


\title{
Corte Internacional de Justicia \\ Año 2016
}

\section{6}

\section{7 de marzo}

\section{Lista General}

$\mathrm{N}^{\mathrm{o}} 155$

17 de marzo de 2016

\author{
Presuntas violaciones de derechos soberanos \\ y espacios marítimos en el mar Caribe \\ (Nicaragua c. Colombia)
}

Objeciones preliminares

Primera objeción preliminar de Colombia.

Argumentos de Colombia - La Corte carece de jurisdicción ratione temporis bajo el Pacto de Bogotá - La denuncia del Pacto es gobernada por el artículo LVI - Efecto inmediato de la notificación de la denuncia.

Argumentos de Nicaragua - El artículo XXXI del Pacto concede jurisdicción en tanto el tratado siga vigente - Bajo el artículo LVI, el Pacto sigue vigente por un año después de la fech a de notificación de la denuncia - La Corte tiene jurisdicción ratione temporis en tanto la demanda de Nicaragua fue presentada menos de un año después de la notificación de la denuncia de Colombia.

Análisis de la Corte - Fecha crítica para establecer jurisdicción - Efectos de la denuncia determinados por el primer párrafo del artículo LVI - Cuestión sobre si el segundo párrafo del artículo LVI altera el efecto del primer párrafo - El segundo párrafo confirma que los procedimientos iniciados antes de la notificación de la denuncia pueden continuar independientemente de esa denuncia - Procedimientos iniciados durante el período de un año son procedimientos iniciados cuando el Pacto aún tiene vigencia - La interpretación de Colombia implicaría que la mayoría de los artículos del Pacto perderían efecto mientras el Pacto sigue vigente - La interpretación de Colombia no es consistente con el objeto y fin del Pacto - La interpretación de Colombia no necesariamente le da effet utile al segundo párrafo del articulo LVI - Se rechaza la primera objeción preliminar de Colombia. 
Segunda objeción preliminar de Colombia según la cual no existió ninguna disputa entre las partes antes de la presentación de la demanda.

Fecha crítica - Existencia de la disputa entre las partes como condición para la jurisdicción de la Corte - Dos pretensiones principales presentadas por Nicaragua - La primera pretensión concierne a las presuntas violaciones de derechos soberanos y espacios marítimos de Nicaragua declarados por la sentencia de 2012 de la Corte como nicaragüenses - Segunda pretensión relativa al incumplimiento de la obligación de no usar o amenazar con el uso de la fuerza por parte de Colombia.

Argumentos de Colombia - Antes de la fecha crítica, Nicaragua nunca elevó sus quejas relativas a las presuntas violaciones realizadas por Colombia-Colombia nunca ha rechazado la sentencia de 2012 - El Decreto Presidencial 1946 sobre una 'zona contigua integral' no es concerniente a ningún asunto tratado por la Corte - No existe evidencia de confrontación entre las fuerzas de las partes.

Argumentos de Nicaragua - Altos oficiales gubernamentales de Colombia públicamente han rechazado la sentencia de 2012 - La zona contigua integral' contenida en el Decreto 1946 no es consistente con el derecho internacional - El Decreto 1946 busca atribuirle a Colombia espacios maritimos que la Corte en su sentencia de 2012 ha determinado que pertenecen a Nicaragua - Colombia presuntamente ha acosado con regularidad a las embarcaciones de pesca nicaragüenses en aguas nicaragüenses.

Análisis de la Corte - Primera pretensión de Nicaragua - Las partes tienen diferentes posiciones sobre las implicaciones legales de la proclamación por Colombia de su 'zona contigua integral' en el Decreto 1946 - No bay negación por Colombia de que esté continuando el ejercicio de jurisdicción en espacios maritimos que Nicaragua reclama como suyos - La protesta formal no es necesaria como condición para la existencia de una disputa - A la fecha de la presentación de la demanda, una disputa existía en relación con la primera pretensión de Nicaragua - Segunda pretensión de Nicaragua - No hay evidencia de que Colombia usara o bubiera amenazado con usar la fuerza en el área en cuestión antes de la fecha crítica - La segunda objeción preliminar de Colombia se rechaza frente a la primera pretensión de Nicaragua y se acepta frente a la segunda pretensión.

Tercera objeción preliminar de Colombia.

Argumentos de Colombia - La Corte carece de jurisdicción en tanto los requisitos contenidos en el artículo II del Pacto no se han cumplido - Opinión de ambas partes de que la disputa no puede ser resuelta por negociaciones es necesaria - Los dos lados se mantuvieron dispuestos a resolver sus diferencias mediante negociaciones directas. 
Argumentos de Nicaragua - El artículo II del Pacto requiere que una de las partes fuera de la opinión de que la disputa no podía ser resuelta por negociaciones Las partes no consideraban la solución de la disputa como posible - La voluntad de Nicaragua a negociar un tratado con Colombia se limitaba a la implementación de la sentencia de 2012 - El objeto de las negociaciones entre las partes es totalmente ajeno al objeto de la disputa.

Consideraciones de la Corte sobre el artículo II del Pacto - Discrepancia entre el texto francés y los otros tres textos oficiales del articulo II - Aproximación tomada en la sentencia de 1988 - No bay necesidad de resolver el problema presentado por la discrepancia textual - Los asuntos identificados para posible diálogo entre las partes son distintos al objeto de la disputa - No hay evidencia de que las partes contemplaran negociaciones sobre la materia de la disputa a la fecha de la presentación de la demanda - Se rechaza la tercera objeción preliminar de Colombia.

Cuarta objeción preliminar de Colombia en cuanto a que la Corte carece de jurisdicción inherente' para abordar la disputa.

La jurisdicción ya ha sido establecida sobre la base del artículo XXXI del Pacto frente a la primera pretensión de Nicaragua. No hay necesidad para la Corte de abordar la alegación de Nicaragua sobre 'jurisdicción inberente' - No bay razón para pronunciarse sobre la cuarta objeción preliminar de Colombia.

Quinta objeción preliminar de Colombia según la cual la Corte no puede abordar una disputa relativa al cumplimiento de una sentencia anterior.

No hay necesidad de que la Corte se pronuncie sobre la quinta objeción de Colombia en lo que se relaciona a jurisdicción inherente - La quinta objeción preliminar debe ser abordada en relación con la jurisdicción bajo el Pacto de Bogotá - Nicaragua no busca la ejecución de la sentencia de 2012 - La quinta objeción de Colombia es rechazada.

\section{Sentencia}

Presentes: presidente ABRAHAM, vicepresidente YUSUF, jueces OWADA, TOMKA, BENNOUNA, CANÇADO TRINDADE, GREENWOOD, XUE, DONOGHUE, GAJA, SEBUTINDE, BHANDARI, ROBINSON, GEVORGLAN; jueces ad hoc DAUDET, CARON; secretario COUVREUR. 
En el caso relativo a las Presuntas violaciones de derechos soberanos y espacios marítimos en el mar Caribe.

Entre

La República de Nicaragua, representada por

S. E. Sr. Carlos José Argüello Gómez, Embajador de la República de Nicaragua ante el Reino de los Países Bajos,

como agente y abogado;

Sr. Vaughan Lowe, Q.C., antiguo profesor Chichele, Derecho Internacional Público, Universidad de Oxford, miembro asociado del Institut de Droit International,

Sr. Alex Oude Elferink, Director delegado, Netherlands Institute for the Law of the Sea, profesor de Derecho Internacional del Mar, Universidad de Utrecht,

Sr. Alain Pellet, profesor de la Universidad Paris Ouest, Nanterre La Défense, antiguo miembro y Presidente de la Comisión de Derecho Internacional, miembro asociado del Institut de Droit International,

Sr. Antonio Remiro Brotóns, profesor de Derecho Internacional, Universidad Autónoma, Madrid, miembro del Institut de Droit International, como consejeros y abogados;

Sr. César Vega Masís, Director de Asuntos Jurídicos, Soberanía y Territorio, Ministerio de Relaciones Exteriores,

Sr. Walner Molina Pérez, consultor jurídico, Ministerio de Relaciones Exteriores,

Sr. Julio César Saborio, consultor jurídico, Ministerio de Relaciones Exteriores,

como consejeros;

Sr. Edgardo Sobenes Obregón, consejero, Embajada de Nicaragua en el Reino de los Países Bajos, 
Sra. Claudia Loza Obregón, Primera Secretaria, Embajada de Nicaragua en el Reino de los Países Bajos,

Sr. Benjamín Samson, candidato a Doctor $(\mathrm{PhD})$, Centro de Derecho Internacional de Nanterre (CEDIN), Universidad Paris Ouest, Nanterre La Défense,

Sra. Gimena González,

como consejero asistente;

Sra. Sherly Noguera de Argüello, Cónsul General de la República de Nicaragua,

como administrador,

$y$

La República de Colombia, representada por

S. E. Sra. María Ángela Holguín Cuéllar, Ministra de Relaciones Exteriores,

S. E. Sr. Francisco Echeverri Lara, Viceministro de Asuntos Multilaterales, Ministerio de Relaciones Exteriores,

como autoridades nacionales;

S. E. Sr. Carlos Gustavo Arrieta Padilla, antiguo juez del Consejo de Estado de Colombia, antiguo Procurador General de la Nación y antiguo Embajador de Colombia ante el Reino de los Países Bajos,

como agente;

S. E. Sr. Manuel José Cepeda Espinosa, antiguo presidente de la Corte Constitucional colombiana, antiguo delegado permanente de Colombia ante la UNESCO y antiguo Embajador de Colombia ante la Confederación Suiza,

como coagente;

Sr. W, Michael Reisman, profesor McDougal de Derecho Internacional en la Facultad de Derecho de Yale, miembro del Institut de Droit International,

Sr. Rodman R. Bundy, antiguo avocat à la Cour d'appel de Paris, miembro de la barra de Nueva York, Eversheds LLP, Singapore, 
Sir Michael Wood, KCMG, miembro de la barra de Inglaterra y Gales, miembro de la Comisión de Derecho Internacional,

Sr. Tulio Treves, miembro del Institut de Droit International, consultor sénior en Derecho Internacional Público, Curtis, Mallet-Prevost, Colt \& Mosle LLP, Milán, profesor, Universidad de Milán,

Sr. Eduardo Valencia-Ospina, miembro de la Comisión de Derecho Internacional, Presidente de la Sociedad Latinoamericana de Derecho Internacional,

Sr. Matthias Herdegen, Dr. h.c., profesor de Derecho Internacional, Director del Instituto de Derecho Internacional de la Universidad de Bonn,

como consejeros y abogados;

S. E. Sr. Juan José Quintana Aranguren, Embajador de Colombia ante el Reino de los Países Bajos, representante permanente de Colombia ante la Organización para la Prohibición de Armas Químicas, antiguo representante permanente de Colombia ante las Naciones Unidas en Ginebra,

S. E. Sr. Andelfo García González, Embajador de la República de Colombia ante el Reino de Tailandia, profesor de Derecho Internacional, antiguo Viceministro de Relaciones Exteriores,

Sra. Andrea Jiménez Herrera, consejera, Embajada de la República de Colombia ante el Reino de los Países Bajos,

Sra. Lucía Solano Ramírez, Segunda Secretaria, Embajada de la República de Colombia ante el Reino de los Países Bajos,

Sr. Andrés Villegas Jaramillo, coordinador, Grupo de Asuntos ante la CIJ, Ministerio de Relaciones Exteriores,

Sr. Giovanny Andrés Vega Barbosa, Grupo de Asuntos ante la CIJ, Ministerio de Relaciones Exteriores,

Sra. Ana María Durán López, Grupo de Asuntos ante la CIJ, Ministerio de Relaciones Exteriores,

Sr. Camilo Alberto Gómez Niño, Grupo de Asuntos ante la CIJ, Ministerio de Relaciones Exteriores,

Sr. Juan David Veloza Chará, Tercer Secretario, Grupo de Asuntos ante la CIJ, Ministerio de Relaciones Exteriores,

como asesores jurídicos;

Almirante Luis Hernán Espejo, Armada Nacional de Colombia, 
Capitán de navío William Pedroza, Oficina de Asuntos internacionales, Armada Nacional de Colombia,

Capitán de fragata Hermann León, Dirección Marítima (DIMAR), Armada Nacional de Colombia,

Sr. Scott Edmonds, cartógrafo, International Mapping,

Sr. Thomas Frogh, cartógrafo, International Mapping,

como consejeros técnicos;

Sra. Charis Tan, abogada y litigante, Singapur, miembro de la Barra de New York, litigante, Inglaterra y Gales, Eversheds LLP, Singapur,

Sr. Eran Sthoeger, LLM, New York University School of Law,

Sr. Renato Raymundo Treves, asociado, Curtis, Mallet-Prevost, Colt \& Mosle LLP, Milán,

Sr. Lorenzo Palestini, candidato a PhD, Institute of International and Development Studies, Ginebra

como asistentes jurídicos,

La Corte,

compuesta según se indicó arriba,

tras deliberar

profiere la siguiente sentencia:

1. El 26 de noviembre de 2013, el gobierno de la República de Nicaragua (en adelante 'Nicaragua') depositó en el Registro de la Corte la demanda contra la República de Colombia (en adelante 'Colombia') respecto a la disputa en relación con "las violaciones de los derechos de soberanía de Nicaragua y las zonas marítimas declaradas por sentencia del 19 de noviembre de 2012 [en el caso relativo a la Controversia territorial y marítima (Nicaragua c. Colombia)] y la amenaza del uso de la fuerza por parte de Colombia con el fin de poner en práctica estas violaciones".

En su demanda, Nicaragua busca fundamentar la competencia de la Corte el artículo XXXI del Tratado Americano de Soluciones Pacíficas firmado el 30 de abril de 1948, denominado oficialmente, de acuerdo con su artículo LX, como el 'Pacto de Bogotá' (como se referirá en adelante).

Nicaragua afirma que, alternativamente, la competencia de la Corte "se encuentra en su poder inherente para pronunciarse sobre las acciones requeridas por sus fallos”. 
2. De conformidad con el artículo 40, párrafo 2, del Estatuto de la Corte, el Secretario comunicó inmediatamente la solicitud al gobierno de Colombia; y, en virtud del apartado 3 de dicho artículo, todos los demás Estados con derecho a comparecer ante la Corte fueron notificados de la solicitud.

3. Dado que la Corte no cuenta entre sus miembros con ningún juez de la nacionalidad de las partes, cada parte procedió a ejercer el derecho que le confiere el artículo 31, apartado 3, del Estatuto de designar un juez ad hoc para el caso. Nicaragua eligió primero el Sr. Gilbert Guillaume, quien renunció el 8 de septiembre de 2015, y, posteriormente, el Sr. Yves Daudet. Colombia designó al Sr. David Caron.

4. Mediante providencia del 3 de febrero de 2014, la Corte fija el 3 de octubre de 2014 como el plazo para la presentación de la memoria de Nicaragua y el 3 de junio de 2015 para la presentación de la contramemoria de Colombia. Nicaragua presentó su memoria dentro del plazo indicado.

5. El 19 de diciembre de 2014, dentro del plazo establecido por el artículo 79, párrafo 1, del Reglamento de la Corte, Colombia opuso excepciones preliminares a la competencia de la Corte. En consecuencia, por providencia del 19 de diciembre de 2014, el Presidente, señalando que, en virtud del artículo 79, párrafo 5, del Reglamento de la Corte, se suspendió el procedimiento sobre el fondo del asunto y, teniendo en cuenta la Directriz Práctica V, fijada el 20 de abril del año 2015 como fecha límite para la presentación por parte de Nicaragua de un escrito con sus observaciones y conclusiones sobre las excepciones preliminares interpuestas por Colombia. Nicaragua presentó su declaración dentro del plazo establecido. Así pues, el asunto quedó listo para la audiencia en relación con las excepciones preliminares.

6. De conformidad con las instrucciones de la Corte en virtud del artículo 43 del Reglamento de la Corte, el Secretario envió a los Estados partes del Pacto de Bogotá las notificaciones previstas en el artículo 63, párrafo 1, del Estatuto de la Corte. De conformidad con lo dispuesto en el artículo 69, párrafo 3, del Reglamento de la Corte, el Secretario remitió también a la Organización de los Estados Americanos (en adelante la 'OEA') la notificación prevista en el artículo 34, párrafo 3, del Estatuto de la Corte. Según lo previsto en el artículo 69, párrafo 3, del Reglamento de la Corte, el Secretario transmitió los escritos a la OEA y preguntó a la organización si tenía, o no, intención de presentar observaciones por escrito en el sentido de dicho artículo. El Secretario señaló además que, en vista del hecho de que la fase actual del proceso estaba relacionada con la 
cuestión de la competencia, las observaciones escritas debían limitarse a dicha cuestión. El Secretario General de la OEA indicó que la organización no tenía intención de presentar tales observaciones.

7. Respecto al artículo 53, párrafo 1, del Reglamento de la Corte, el gobierno de la República de Chile pidió que se le facilitaran copias de los escritos y documentos que se habían anexado en el caso. Tras consultar la opinión de las partes al respecto, de conformidad con la misma disposición, el Presidente de la Corte decidió acceder a dicha petición. El Secretario comunicó debidamente esta decisión al gobierno de Chile y a las partes.

De conformidad con la misma disposición de las normas, el gobierno de la República de Panamá también pidió que se le facilitaran copias de los escritos y documentos que se anexan en el caso. Esta solicitud se comunicó a las partes a fin de conocer sus opiniones. Mediante carta de fecha 22 de julio de 2015, el agente de Nicaragua declaró que su gobierno no tiene objeciones a que Panamá contara con las copias de los escritos y documentos que se anexan en el caso. Por su parte, mediante carta de fecha 27 de julio de 2015, el agente de Colombia indicó que, aunque su gobierno no tenía objeciones a que Panamá adquiriera copias de las excepciones preliminares interpuestas por Colombia y el escrito de Nicaragua sobre sus observaciones y conclusiones, sí se opuso a que la memoria de Nicaragua estuviese a disposición de Panamá. Teniendo en cuenta las opiniones de las partes, la Corte decidió que se hicieran copias de las excepciones preliminares interpuestas por Colombia y del escrito de Nicaragua sobre sus observaciones y conclusiones, para que fueran puestas a disposición del gobierno de Panamá. La Corte, sin embargo, decidió que no sería apropiado proporcionar copias de la memoria de Nicaragua al gobierno de Panamá. El Secretario debidamente comunicó esta decisión al gobierno de Panamá y a las partes.

8. La Corte, de acuerdo con el artículo 53, párrafo 2, del Reglamento de la Corte, después de obtener las opiniones de las partes, decidió que las copias de las objeciones preliminares de Colombia y las observaciones escritas de Nicaragua serían accesibles al público en el momento de la apertura del procedimiento oral.

9. Las audiencias públicas sobre las excepciones preliminares planteadas por Colombia se llevaron a cabo desde el lunes 28 de septiembre de 2015 hasta el viernes 2 de octubre de 2015, en las cuales la Corte escuchó los argumentos orales y las respuestas: 
Porparte de Colombia: $\quad$ S. E. Sr. Carlos Gustavo Arrieta Padilla, Sir Michael Wood,

Sr. Rodman R. Bundy,

Sr. W. Michael Reisman,

Sr. Eduardo Valencia-Ospina,

Sr. Tullio Treves.

Porparte de Nicaragua: $\quad$ S. E. Sr. Carlos José Argüello Gómez, Sr. Antonio Remiro Brotóns,

Sr. Vaughan Lowe,

Sr. Alain Pellet.

10. En las audiencias, un miembro de la Corte formuló preguntas a las partes, a las que se respondió por escrito dentro del plazo fijado por el Presidente de conformidad con el artículo 61, párrafo 4, del Reglamento de la Corte. De conformidad con el artículo 72 del Reglamento de la Corte, cada una de las partes presentó observaciones sobre las respuestas escritas proporcionadas por el otro.

11. En la demanda, los siguientes reclamos fueron presentados por Nicaragua:

"Sobre la base de los elementos de hecho y de derecho del presente asunto antes expuestos, Nicaragua, reservándose el derecho de ampliar, enmendar o modificar esta demanda, solicita a la Corte que falle y declare que Colombia ha incumplido:

- su obligación de no utilizar ni amenazar con utilizar la fuerza en virtud del artículo 2(4) de la Carta de las Naciones Unidas y el derecho internacional consuetudinario;

- su obligación de no violar las zonas marítimas de Nicaragua, tal como se delimita en el parágrafo 251 de la sentencia de la CIJ del 19 de noviembre de 2012, así como los derechos y la jurisdicción en estas zonas de soberanía de Nicaragua;

- su obligación de no violar los derechos de Nicaragua bajo la costumbre internacional, como se refleja en las partes V y VI de la Convención de las Naciones Unidas sobre Derecho del Mar;

- y que, en consecuencia, Colombia está obligada a cumplir con la sentencia del 19 de noviembre de 2012, anular todas las consecuencias 
legales y materiales de sus hechos internacionalmente ilícitos, y reparar íntegramente el daño causado por esos actos".

12. En el procedimiento escrito sobre el fondo del asunto, se presentaron las siguientes conclusiones en nombre del gobierno de Nicaragua:

"1. Por las razones expuestas en el presente memorial, la República de Nicaragua solicita a la Corte que falle y declare que, por su conducta, la República de Colombia ha violado:

a) la obligación de no violar las zonas marítimas de Nicaragua tal como se delimita en el apartado 251 de la sentencia del tribunal del 19 de noviembre 2012, así como los derechos y la jurisdicción en estas zonas de la soberanía de Nicaragua;

b) su obligación de no utilizar ni amenazar con utilizar la fuerza en virtud del artículo 2(4) de la Carta de las Naciones Unidas y el derecho internacional consuetudinario;

c) y que, en consecuencia, Colombia tiene la obligación de deshacer todas las consecuencias legales y materiales de sus hechos internacionalmente ilícitos, y reparar íntegramente el daño causado por esos actos.

2. Nicaragua también solicita a la Corte que falle y declare que Colombia debe:

a) poner fin a todos sus continuos actos internacionalmente ilícitos que afecten o puedan afectar a los derechos de Nicaragua.

b) En la medida de lo posible, restablecer la situación al status quo ante,

i. revocando las leyes y reglamentos promulgados por Colombia, que son incompatibles con el fallo de la Corte del 19 de noviembre de 2012 incluyendo las disposiciones de los decretos 1946 del 9 de septiembre de 2013 y 1119 del 17 de junio de 2014 a las zonas marítimas que han sido reconocidas como parte de la jurisdicción o bajo los derechos de soberanía de Nicaragua;

ii. revocando los permisos concedidos a los buques pesqueros que operan en aguas de Nicaragua; y

iii. asegurando que la decisión de la Corte Constitucional de Colombia del 2 de mayo de 2014 o de cualquier otra autoridad nacional 
no impedirá el cumplimiento de la sentencia de la Corte del 19 de noviembre de 2012.

c) Pagar todos los daños causados, en tanto no sean cubiertos por la restitución, incluyendo la pérdida de ingresos resultantes de la pérdida de inversión, provocada por las declaraciones amenazantes de las más altas autoridades de Colombia, entre ellos la amenaza o al uso de la fuerza por parte de la Armada Nacional de Colombia contra los barcos de pesca de Nicaragua [o naves de exploración y explotación del suelo y el subsuelo de la plataforma continental de Nicaragua] y barcos de pesca de terceros Estados con licencia de Nicaragua, así como de la explotación de aguas de Nicaragua por los buques de pesca ilegalmente 'autorizados' por Colombia, siendo el monto de la compensación decidido en una fase subsecuente del caso.

d) Dar garantías adecuadas de no repetición de sus actos internacionalmente ilícitos".

13. En las excepciones preliminares, se presentaron las siguientes conclusiones en nombre del gobierno de Colombia:

"Por las razones expuestas en el presente procedimiento, la República de Colombia solicita a la Corte que falle y declare que carece de jurisdicción sobre el procedimiento iniciado por Nicaragua, en su solicitud de 26 de noviembre de 2013".

En la declaración escrita de sus observaciones y conclusiones sobre las excepciones preliminares planteadas por Colombia, se presentaron las siguientes conclusiones en nombre del gobierno de Nicaragua:

"Por las razones mencionadas anteriormente, la República de Nicaragua solicita a la Corte que falle y declare que las excepciones preliminares presentadas por la República de Colombia en relación con la competencia de la Corte no son válidas".

14. En los procedimientos orales sobre las excepciones preliminares, se presentaron las siguientes conclusiones por las partes:

\section{En nombre del gobierno de Colombia,}

en la audiencia del 30 de septiembre de 2015: 
"Por los motivos enunciados en los procedimientos escritos y orales, sobre las excepciones preliminares, la República de Colombia solicita a la Corte que falle y declare que carece de jurisdicción sobre el procedimiento iniciado por Nicaragua, en su solicitud de 26 de noviembre de 2013, y que dicha demanda sea rechazada”.

En nombre del gobierno de Nicaragua,

en la audiencia del 2 de octubre de 2015:

"En vista de las razones expuestas por Nicaragua en sus observaciones escritas y durante las audiencias, la República de Nicaragua solicita a la Corte:

- desestimar las excepciones preliminares de la República de Colombia; y

- proceder con el examen de los méritos del caso".

\section{Introducción}

15. Se recuerda que, en el presente procedimiento, Nicaragua pretende fundamentar la competencia de la Corte sobre el artículo XXXI del Pacto de Bogotá. De acuerdo con esta disposición, las partes en el Pacto reconocen la jurisdicción de la Corte como obligatoria en todos los "conflictos de carácter jurídico" (véase el párrafo 21 infra).

16. Por otra parte, Nicaragua sostiene que la Corte tiene una competencia inherente para conocer de las controversias relativas al incumplimiento de sus fallos, y que en el presente procedimiento existe tal jurisdicción inherente, dado que la actual disputa surge de incumplimiento por parte de Colombia, de la sentencia del 19 de noviembre de 2012, en el caso relativo a la Controversia territorial y maritima (Nicaragua c. Colombia) (CIJ Reportes 2012 [II], p. 624) (en adelante 'sentencia de 2012').

17. Colombia ha planteado cinco excepciones preliminares a la competencia de la Corte. De acuerdo con la primera excepción, la Corte carece de competencia en razón del tiempo en el marco del Pacto de Bogotá debido a que los procedimientos fueron instituidos por Nicaragua el 26 de noviembre de 2013, después de la notificación de Colombia 
de denuncia del Pacto el 27 de noviembre de 2012. En su segunda objeción, Colombia sostiene que, aun si la Corte no se atiene a la primera objeción, todavía no tiene jurisdicción en el marco del Pacto de Bogotá porque no había ninguna diferencia entre las partes al 26 de noviembre de 2013, fecha en que se presentó la demanda. Colombia sostiene en su tercera objeción que, incluso si la Corte no se atiene a la primera objeción, el tribunal todavía no tiene jurisdicción en el marco del Pacto de Bogotá, ya que, en el momento de la presentación de la demanda, las partes no consideraban que la supuesta controversia "[no podía] ser resuelta por negociaciones directas a través de los canales diplomáticos habituales", como se requiere, a juicio de Colombia, en el artículo II del Pacto de Bogotá antes de recurrir a los procedimientos de resolución de disputas del Pacto. En su cuarta excepción, Colombia rechaza la afirmación de Nicaragua de que la Corte tiene una "competencia inherente" que le permita pronunciarse sobre el supuesto incumplimiento de una sentencia anterior. Por último, de acuerdo con la quinta excepción de Colombia, la Corte no tiene competencia en materia de ejecución de una sentencia anterior, que es, en su opinión, el verdadero objeto de las reclamaciones de Nicaragua en el presente procedimiento.

18. En sus observaciones escritas y presentaciones finales en el juicio oral, Nicaragua solicitó a la Corte que rechace las objeciones preliminares de Colombia en su totalidad (véanse los parágrafos 13 y 14 supra).

19. La Corte pasa a considerar estas objeciones en el orden presentado por Colombia.

\section{Primera excepción preliminar}

20. La primera excepción preliminar de Colombia hace referencia a que el artículo XXXI del Pacto de Bogotá no puede servir de base para dar jurisdicción a la Corte, porque Colombia había notificado la denuncia del Pacto antes de que Nicaragua presentara su demanda en el presente caso. De acuerdo con lo expuesto por Colombia, la notificación tuvo un efecto inmediato sobre la jurisdicción de la Corte en virtud del artículo XXXI, dando como resultado que la Corte carece de jurisdicción respecto de cualquier procedimiento iniciado después de que la notificación fuera transmitida.

21. El artículo XXXI del Pacto de Bogotá señala que: 
"De conformidad con el inciso 2 del artículo 36 del Estatuto de la Corte Internacional de Justicia, las altas partes contratantes declaran que reconocen respecto a cualquier otro Estado americano como obligatoria ipso facto, sin necesidad de ningún convenio especial mientras esté vigente el presente tratado, la jurisdicción de la expresada Corte en todas las controversias de orden jurídico que surjan entre ellas y que versen sobre:

a) la interpretación de un tratado;

b) cualquier cuestión de derecho internacional;

c) la existencia de todo hecho que, si fuere establecido, constituiría la violación de una obligación internacional;

d) la naturaleza o extensión de la reparación que ha de hacerse por el quebrantamiento de una obligación internacional".

22. La denuncia del Pacto de Bogotá se rige por el artículo LVI, que dice:

“El presente tratado regirá indefinidamente, pero podrá ser denunciado mediante aviso anticipado de un año, transcurrido el cual cesará en sus efectos para el denunciante, quedando subsistente para los demás signatarios. La denuncia será dirigida a la Unión Panamericana, que la transmitirá a las otras partes contratantes.

La denuncia no tendrá efecto alguno sobre los procedimientos pendientes iniciados antes de transmitido el aviso respectivo".

23. El 27 de noviembre de 2012, Colombia notificó la denuncia por medio de una nota diplomática del Ministerio de Relaciones Exteriores al Secretario General de la OEA, como cabeza de la Secretaría General de la OEA (la sucesora de la Unión Panamericana). Esta comunicación señala que la denuncia de Colombia "rige a partir del día de hoy respecto de los procedimientos que se inicien a partir de la presente notificación, de conformidad con el inciso 2 del artículo LVI".

24. La demanda en el presente caso fue sometida a la Corte después de la transmisión de la notificación de la denuncia de Colombia, pero antes de que el período de un año mencionado en el primer párrafo del artículo LVI hubiese transcurrido. 
25. Colombia sostiene que el artículo LVI del Pacto de Bogotá debe ser interpretado de acuerdo con las normas del derecho internacional consuetudinario sobre la interpretación de los tratados, consagradas en los artículos 31 a 33 de la Convención de Viena de 1969 sobre el Derecho de los Tratados (en adelante, la 'Convención de Viena'). Colombia se basa, en particular, en la regla general de interpretación del artículo 31 de la Convención de Viena, que establece que "un tratado deber de interpretarse de buena fe conforme al sentido corriente que haya de atribuirse a los términos del tratado en el contexto de éstos y teniendo en cuenta su objeto y fin". Según Colombia, la aplicación de la regla general de interpretación de los tratados debe llevar a la conclusión de que los procedimientos iniciados después de la transmisión de una notificación de denuncia se ven afectados por la denuncia.

26. Colombia sostiene que la implicación natural de la disposición expresa en el párrafo segundo del artículo LVI del Pacto, de que la denuncia no tendrá efecto alguno sobre los procedimientos pendientes iniciados antes de la transmisión de una notificación de denuncia, es que es eficaz con respecto a los procedimientos iniciados después de esa fecha. Tal efecto debe seguir, de acuerdo con Colombia, desde la aplicación hasta el segundo párrafo del artículo LVI de una interpretación contraria de la que fue aplicada por la Corte en su sentencia del 16 de abril de 2013 en el caso relativo a la Controversia fronteriza (Burkina Faso/Niger) (CIJ Reportes 2013, pp. 81-82, párrs. 87-88). Por otra parte, adoptar una interpretación diferente negaría el efecto útil del segundo párrafo y, por lo tanto, en contra del principio de que todas las palabras en un tratado deberían tener efecto útil. Colombia rechaza la idea de que su interpretación del párrafo segundo del artículo LVI negaría efecto útil al primer párrafo de esta disposición. A pesar de que Colombia acepta que su interpretación significaría que ninguno de los diferentes procedimientos previstos en los capítulos 2 a 5 del Pacto podría ser iniciado por o en contra de un Estado que había dado notificación de esta durante el año en que el tratado se mantuvo en vigor de acuerdo con el primer párrafo del artículo LVI, sostiene que importantes obligaciones sustantivas contenidas en los demás capítulos del Pacto permanecerán en vigor durante el período de un año, por lo que el primer párrafo del artículo LVI tendría un efecto claro.

27. Colombia sostiene que su interpretación del artículo LVI se confirma por el hecho de que, si las partes en el Pacto hubieran querido establecer que la denuncia no afectaría a los procedimientos incoados durante el período de un año de aviso, fácilmente lo podrían haber indicado 
expresamente, mediante la adopción de una redacción similar a las disposiciones de otros tratados, como el artículo 58, párrafo 2, del Convenio Europeo de Derechos Humanos de 1950, o el artículo 40, párrafo 2, del Convenio Europeo de 1972, relativo a la inmunidad de los Estados. Colombia observa también que la función y el texto del artículo XXXI son muy similares a los del artículo 36, párrafo 2, del Estatuto de la Corte, y que los Estados generalmente se reservan el derecho de retirar sus declaraciones de conformidad con el artículo 36, apartado 2, sin previo aviso.

28. Por último, Colombia sostiene que su interpretación es "también consistente con la práctica de los Estados de las partes en el Pacto" y los travaux préparatoires. Con respecto al primer argumento, que apunta a la falta de reacción, incluso de Nicaragua, a la notificación de la denuncia de Colombia, a pesar de la declaración clara en este de que la denuncia debía entrar en vigor a partir de la fecha de la notificación "con respecto a los procedimientos... iniciada a partir del presente anuncio". También hace hincapié en que no hubo ninguna reacción por parte de otras partes en el Pacto cuando El Salvador dio aviso de denuncia en 1973, a pesar de que en la notificación de esta declaró que "comenzará a surtir efecto a partir de hoy". Con respecto a los trabajos preparatorios, Colombia sostiene que el primer párrafo del artículo LVI fue tomado del artículo $9^{\circ}$ del 1929 Tratado General de Arbitraje Interamericano (y la disposición paralela en el artículo 16 de la Convención General 1929 de Conciliación Interamericana). Colombia sostiene que lo que terminó siendo el segundo párrafo del artículo LVI fue el resultado de una iniciativa adoptada por los Estados Unidos de América en 1938, que fue aceptada por el Comité Jurídico Interamericano en 1947 e incorporada en el texto que fue firmado en 1948. Según Colombia, esta historia demuestra que las partes en el Pacto de Bogotá pretendían incorporar una disposición que limitara el efecto del primer párrafo del artículo LVI.

29. Nicaragua afirma que la competencia de la Corte se determina en el artículo XXXI del Pacto de Bogotá, según el cual Colombia y Nicaragua habían cada uno reconocido la competencia de la Corte "por el tiempo que el presente tratado esté en vigor". El tiempo que permanece el tratado vigente se determina por el primer párrafo del artículo LVI, que dispone que el Pacto sigue en vigor para un Estado que haya hecho una notificación de denuncia por un año, desde la fecha de esa notificación. Desde la fecha 
en que ha de establecerse la jurisdicción de la Corte es aquella en que se presentó la demanda, y dado que la demanda de Nicaragua fue presentada menos de un año después de que Colombia dio la notificación de su denuncia del Pacto, de acuerdo con lo que sostiene Nicaragua, la Corte tiene competencia en el presente caso. Nicaragua sostiene que nada en el segundo párrafo del artículo LVI va en contra de esta conclusión y ninguna inferencia debe establecerse desde el silencio de ese párrafo respecto a los procedimientos iniciados entre la transmisión de la notificación de denuncia y la fecha en que se termina el tratado para el Estado denunciante; en cualquier caso, dichas inferencias no podían prevalecer sobre el texto expreso del artículo XXXI y el primer párrafo del artículo LVI.

30. Esta conclusión se ve reforzada, desde el punto de vista de Nicaragua, por la consideración del objeto y fin del Pacto. Nicaragua recuerda que, según el tribunal, "es bastante claro desde el Pacto que el propósito de los Estados americanos en su elaboración fue reforzar sus compromisos mutuos con respecto al arreglo judicial" - Acciones armadas fronterizas y transfronterizas (Nicaragua c. Honduras), Competencia y admisibilidad, sentencia, CIJ Reportes 1988, p. 89, párr. 46—. La interpretación de Colombia en el segundo párrafo del artículo LVI sería, según lo que sostiene Nicaragua, privar de todo sentido la disposición expresa del artículo XXXI, de que las partes en el Pacto aceptan la jurisdicción de la Corte, siempre que el Pacto esté en vigor entre ellos, así como la disposición expresa del artículo LVI de que el Pacto sigue vigente por un año después de la notificación de denuncia. Según Nicaragua, dicha interpretación también haría que el propósito del Pacto, como lo definió la Corte, fuera inalcanzable durante el período de preaviso de un año.

31. Nicaragua no acepta el argumento de Colombia de que la interpretación de Colombia en el segundo párrafo del artículo LVI aún dejaría obligaciones importantes vigentes, durante el período de un año de aviso. Según Nicaragua, la interpretación de Colombia eliminaría de los efectos del párrafo primero del artículo LVI todos los procedimientos de buenos oficios y mediación (capítulo 2 del Pacto), la investigación y conciliación (capítulo 3), el arreglo judicial (capítulo 4) y el arbitraje (capítulo 5), que en conjunto comprenden 41 de los 60 artículos del Pacto. De las disposiciones restantes, varias — como el artículo LII sobre la ratificación del Pacto y el artículo LIV de adhesión al Pacto- son disposiciones que han servido por completo su propósito y no cumplirían ninguna función durante el período de un año de notificación, mientras que otras — tales como los artículos III a VI— están inextricablemente ligados a los procedimientos 
descritos en los capítulos 2 a 5 y no imponen obligaciones independientes de esos procedimientos. La interpretación de Colombia del artículo LVI implicaría, por lo tanto, dejar solo 6 de 60 artículos del Pacto con alguna función durante el período de un año previsto en el primer párrafo del artículo LVI. Nicaragua también señala que el título del capítulo 1 del Pacto es "Obligación general de resolver las controversias por medios pacíficos" y sostiene que sería extraño interpretar el artículo LVI del Pacto, mantenimiento de este capítulo en vigor, entre un Estado que ha dado aviso de denuncia y de las demás partes en el Pacto, pero no los capítulos que contienen los mismos medios a los que se refiere el capítulo 1.

32. Por último, Nicaragua niega que la práctica de las partes del Pacto de Bogotá o los travaux préparatoires apoyan la interpretación de Colombia. Por lo que se refiere a la práctica, Nicaragua sostiene que nada se puede leer de la ausencia de una respuesta a las notificaciones de denuncia por parte de El Salvador y Colombia, ya que no había ninguna obligación de otras partes en el Pacto de contestar. En cuanto a los travaux préparatoires, ellos no dan razón de porqué lo que se convirtió en el segundo párrafo del artículo LVI se incluyó o sobre cuál es su verdadero significado. Lo más importante es que los travaux préparatoires no contienen nada que sugiera que las partes en el Pacto pretendían, mediante la adición de lo que se convirtió en el segundo párrafo, restringir el alcance del párrafo primero del artículo LVI. En opinión de Nicaragua, el segundo párrafo del artículo LVI, aunque no es necesario, sirve a un propósito útil para hacer claro que la denuncia no afecta a los procedimientos pendientes.

33. El tribunal recuerda que la fecha en que su competencia ha de establecerse es la fecha en que la demanda sea presentada ante la Corte - Aplicación de la Convención para la Prevención y la Sanción del Delito de Genocidio (Croacia c. Serbia), Excepciones preliminares, sentencia, CIJ Reportes 2008, pp. 437-438, párrs. 79-80; Aplicación de la Convención para la Prevención y la Sanción del Delito de Genocidio (Bosnia y Herzegovina c. Yugoslavia), Excepciones preliminares, sentencia, CIJ Reportes de 1996 (II), p. 613, párr. 26-. Una consecuencia de esta regla es que "la eliminación, después de que una solicitud ha sido presentada, de un elemento en el que la competencia de la Corte es dependiente no tiene y no puede tener ningún efecto retroactivo" - Aplicación de la Convención para la Prevención y la Sanción del Delito de Genocidio (Croacia c. Serbia), Excepciones preliminares, sentencia, 
CIJ Reportes 2008, p. 438, párr. 80-. Por lo tanto, incluso si la disposición del tratado por el que se atribuye competencia a la Corte deja de estar en vigor entre el demandante y el demandado, o la declaración de cualquiera de las partes en virtud del artículo 36, párrafo 2, del Estatuto de la Corte, expira o se retira, después de que la demanda ha sido presentada, esta circunstancia no priva a la Corte de jurisdicción. Como se ha declarado, en el caso Nottebohm:

"Cuando se presenta una solicitud en un momento en que la ley en vigor entre las partes implique la jurisdicción obligatoria de la Corte [...] la presentación de la demanda no es más que la condición necesaria para que la cláusula de jurisdicción obligatoria produzca sus efectos en relación con la reclamación formulada en la demanda. Una vez que esta condición ha sido satisfecha, la Corte debe hacer frente a la demanda; es competente para ocuparse de todos sus aspectos, ya se refieran a la competencia, la admisibilidad o sobre el fondo. Un hecho extrínseco como el lapso posterior de la declaración, como consecuencia de la expiración del plazo o por denuncia, no puede privar a la Corte de la jurisdicción ya establecida". —Nottebohm (Liechtenstein c. Guatemala), Excepción preliminar, sentencia, CIJ Reportes 1953, p. 123-.

34. Por el artículo XXXI, las partes en el Pacto de Bogotá reconocen como obligatoria la jurisdicción de la Corte, "mientras que el presente tratado esté en vigor”. El primer párrafo del artículo LVI establece que, a raíz de la denuncia del Pacto por un Estado parte, el Pacto permanecerá en vigor entre el Estado denunciante y las demás partes, por un período de un año después de la notificación de denuncia. No se discute que, si dichas disposiciones existieran solas, serían suficientes para atribuir la competencia en el presente caso. El Pacto estaba aún en vigor entre Colombia y Nicaragua en la fecha en que se presentó la demanda y, de conformidad con la norma considerada en el párrafo 33, el hecho de que, posteriormente, el Pacto dejó de estar en vigor entre ellos no afecta la jurisdicción. La única cuestión planteada por la primera excepción preliminar de Colombia, por lo tanto, es si el segundo párrafo del artículo LVI altera lo que de otro modo habría sido el efecto del primer párrafo, como para llegar a la conclusión de que la Corte carece de competencia respecto de las actuaciones, sin perjuicio de que este procedimiento se instituyera mientras que el Pacto estaba aún en vigor entre Nicaragua y Colombia. 
35. Esa pregunta tiene que ser contestada por la aplicación de las disposiciones pertinentes del Pacto de Bogotá sobre las normas de interpretación de los tratados consagradas en los artículos 31 a 33 de la Convención de Viena. A pesar de que la Convención no está en vigor entre las partes y no es, en cualquier caso, aplicable a los tratados celebrados antes de su entrada en vigor, tales como el Pacto de Bogotá, está bien establecido que los artículos 31 a 33 de la Convención reflejan las reglas de derecho internacional consuetudinario - Avena y otros nacionales mexicanos (México c. Estados Unidos de América), sentencia, CIJ Reportes 2004 (I), p. 48, párr. 83; LaGrand (Alemania c. Estados Unidos de América), sentencia, CIJ Reportes 2001, p. 502, párr. 101; Plataformas petroliferas (Irán c. Estados Unidos de América), Excepción preliminar, sentencia, CIJ Reportes 1996 (II), p. 812, párr. 23; Controversia territorial (Jamabiriya árabe Libia/Chad), sentencia, CIJ Reportes 1994, p. 21, párr. 41; laudo arbitral del 31 de julio de 1989 (Guinea Bissau c. Senegal), sentencia, CIJ Reportes 1991, p. 70, párr. 48- Las partes acuerdan que estas reglas son aplicables. El artículo 31, que establece la regla general de interpretación, requiere que "un tratado deberá interpretarse de buena fe conforme al sentido corriente que haya de atribuirse a los términos del tratado en el contexto de éstos y teniendo en cuenta su objeto y fin".

36. El argumento de Colombia con respecto a la interpretación del segundo párrafo del artículo LVI se basa, no en el sentido corriente de los términos utilizados en esta disposición, sino en una inferencia que puede extraerse de lo que no dice el párrafo. Ese párrafo no dice nada con respecto a los procedimientos iniciados con posterioridad a la transmisión de la notificación de esta, pero antes de la expiración del período de un año previsto en el párrafo primero del artículo LVI. Colombia solicita a la Corte que, de ese silencio del mencionado párrafo, infiera que esta carece de competencia respecto de los procedimientos iniciados después de que la notificación de denuncia ha sido dada. Según Colombia, la inferencia debe hacerse a pesar de que el Pacto sigue en vigor para el Estado denunciante, porque aún no ha transcurrido el plazo de un año de preaviso establecido en el primer párrafo del artículo LVI. La inferencia pretende que se siga una interpretación a contrario de la disposición.

37. Una interpretación contraria a una disposición convencional - por la cual se dice que el hecho de que la disposición prevé expresamente una categoría de situaciones para justificar la inferencia de que se excluyen otras categorías comparables - se ha empleado tanto por la Corte —ver, por ejemplo, Controversia territorial y marítima (Nicaragua c. Colombia), 
Solicitud de Honduras de permiso para intervenir, sentencia, CIJ Reportes 2011 (II), p. 432, párr. 29- y de la Corte Permanente de Justicia Internacional — Ss 'Wimbledon', juicio, 1923, сPJI, Series A, No 1, pp. 23-24-. Tal interpretación solamente se justifica cuando es apropiado a la luz del texto de todas las disposiciones en cuestión su contexto y el objeto y fin del tratado. Además, incluso cuando se justifica una interpretación contraria, es importante determinar con precisión qué inferencia requiere su aplicación en cualquier caso.

38. El segundo párrafo del artículo LVI establece que "la denuncia no tendrá efecto alguno sobre los procedimientos pendientes iniciados antes de transmitido el aviso respectivo". Sin embargo, no es la denuncia por sí misma la cual es capaz de tener un efecto sobre la competencia de la Corte en virtud del artículo XXXI del Pacto, sino la terminación del tratado (entre el Estado denunciante y las demás partes) que resulta de la denuncia. Esto se desprende tanto de los términos del artículo XXXI, que establece que las partes en el Pacto reconocen la jurisdicción de la Corte como obligatoria inter se "mientras esté vigente el presente tratado", y del sentido corriente de las palabras utilizadas en el artículo LVI. El primer párrafo del artículo LVI establece que el tratado puede ser terminado por denuncia, pero que se producirá la terminación solo después de un período de un año a partir de la notificación de denuncia. Es, por lo tanto, este primer párrafo el que determina los efectos de denuncia. El segundo párrafo del artículo LVI confirma que los procedimientos iniciados antes de la transmisión de la notificación de denuncia pueden continuar independientemente de la denuncia y que, por lo tanto, su continuación está garantizada con independencia de lo dispuesto en el primer párrafo respecto de los efectos de la denuncia en general.

39. El argumento de Colombia es que, si se aplica una interpretación contraria al segundo párrafo del artículo LVI, entonces se deduce de la afirmación de que "la denuncia no tendrá efecto alguno sobre los procedimientos pendientes iniciados antes de la transmisión de la notificación en particular [de denuncia]" que dicha denuncia tiene un efecto sobre los procedimientos creados después de la transmisión de la notificación. Colombia sostiene que el efecto es que los procedimientos iniciados después de esa fecha quedan totalmente excluidos del tratado. En el caso de actuaciones ante la Corte iniciadas después de dicha fecha, Colombia mantiene que, entonces, estarían fuera del ámbito de competencia atribuida por el artículo XXXI. Sin embargo, esta interpretación es contraria a los términos del artículo XXXI, que establece que las partes en el Pacto 
reconocen la jurisdicción de la Corte como obligatoria "mientras esté vigente el presente tratado".

El segundo párrafo del artículo LVI está abierto a una interpretación diferente, que es compatible con el texto del artículo XXXI. De acuerdo con esta interpretación, los procedimientos iniciados antes de la transmisión de la notificación de la denuncia pueden continuar en cualquier caso, y, por lo tanto, no están sujetos al párrafo primero del artículo LVI, ya que el efecto de denuncia en los procedimientos iniciados después de dicha fecha se rige por el primer párrafo. Debido a que el primer párrafo establece que la denuncia termina el tratado para el Estado denunciante solo después de que haya transcurrido un período de un año, los procedimientos iniciados durante ese año se entienden instituidos mientras que el Pacto sigue vigente. Se encuentran, entonces, en el ámbito de las competencias atribuidas por el artículo XXXI.

40. Por otra parte, de acuerdo con la regla de interpretación consagrada en el artículo 31, párrafo 1, del Convenio de Viena, el texto del segundo párrafo del artículo LVI tiene que ser examinado en su contexto. Colombia admite (véase el parágrafo 26 supra) que su lectura del segundo párrafo tiene el efecto de que, durante el período de un año que el primer párrafo del artículo LVI establece entre la notificación de denuncia y la terminación del tratado para el Estado denunciante, ninguno de los procedimientos de solución de controversias establecidos en los capítulos 2 a 5 del Pacto podrían ser invocados como entre un Estado denunciante y cualquier otra parte en el Pacto. Según Colombia, solo las disposiciones de los demás capítulos del Pacto permanecerían en vigor entre un Estado denunciante y las demás partes, durante el período de un año de aviso. Sin embargo, los capítulos 2 a 5 contienen todas las disposiciones del Pacto que se ocupan de los distintos procedimientos para la solución pacífica de las controversias y, como la Corte procederá a explicar, desempeñan un papel central dentro de la estructura de las obligaciones establecidas por el Pacto. El resultado de la interpretación propuesta por Colombia del párrafo segundo del artículo LVI sería que, durante el año siguiente a la notificación de denuncia, la mayoría de los artículos del Pacto, que contiene sus disposiciones más importantes, no se aplicarían entre el Estado denunciante y las demás partes. Tal resultado es difícil de conciliar con los términos expresados en el párrafo primero del artículo LVI, que establece que "el presente tratado" permanecerá en vigor durante el período de un año, sin distinguir entre diferentes partes del Pacto como Colombia busca hacerlo. 
41. También es necesario considerar si la interpretación de Colombia es compatible con el objeto y el fin del Pacto de Bogotá. Ese objeto y fin son sugeridos por el título completo del Pacto, a saber, el Tratado Americano de Soluciones Pacíficas. El preámbulo indica que el Pacto se adoptó en cumplimiento del artículo XXIII de la Carta de la OEA. El artículo XXIII (actualmente artículo XXVII) expresa que:

"un tratado especial establecerá los medios adecuados para resolver las controversias y determinará los procedimientos pertinentes a cada uno de los medios pacíficos, en forma de no dejar que controversia alguna entre los Estados americanos pueda quedar sin solución definitiva dentro de un plazo razonable".

Ese énfasis en el establecimiento de medios para la solución pacífica de controversias como el objeto y fin del Pacto se ve reforzado por las disposiciones del capítulo 1 del Pacto, que se titula "Obligación general de resolver las controversias por medios pacíficos". Su artículo I señala:

"Las altas partes contratantes, reafirmando solemnemente sus compromisos contraídos por anteriores convenciones y declaraciones internacionales, así como por la Carta de las Naciones Unidas, convienen en abstenerse de la amenaza, del uso de la fuerza o de cualquier otro medio de coacción para el arreglo de sus controversias y en recurrir en todo tiempo a procedimientos pacíficos".

El artículo II dispone:

"Las altas partes contratantes reconocen la obligación de resolver las controversias internacionales por los procedimientos pacíficos regionales antes de llevarlas al Consejo de Seguridad de las Naciones Unidas.

En consecuencia, en caso de que entre dos o más Estados signatarios se suscite una controversia que, en opinión de las partes, no pueda ser resuelta por negociaciones directas a través de los medios diplomáticos usuales, las partes se comprometen a hacer uso de los procedimientos establecidos en este tratado en la forma y condiciones previstas en los artículos siguientes, o bien de los procedimientos especiales que, a su juicio, les permitan llegar a una solución”. 
Por último, la Corte recuerda que, en su sentencia de 1988 en el caso de Acciones armadas, citado en el parágrafo 30 anterior, sostuvo que "el objetivo de los Estados americanos en la redacción [del Pacto] fue reforzar sus compromisos mutuos con respecto al arreglo judicial" - Acciones armadas fronterizas y transfronterizas (Nicaragua c. Honduras), Competencia y admisibilidad, sentencia, CIJ Reportes 1988, p. 89, párr. 46-.

42. Estos factores ponen de manifiesto que el objeto y fin del Pacto es promover la solución pacífica de controversias a través de los procedimientos previstos en el Pacto. Aunque Colombia aduce que la referencia a "procedimientos... regionales" en el primer párrafo del artículo II no se limita a los procedimientos establecidos en el Pacto, el artículo II tiene que ser interpretado en su conjunto. Se desprende de la utilización de la palabra "en consecuencia" al principio del segundo párrafo del artículo II que la obligación de recurrir a los procedimientos regionales, que las partes 'reconocen' en el primer párrafo, debe ser puesto en práctica mediante el empleo de los procedimientos establecidos en los capítulos 2 a 5 del Pacto. Colombia sostiene que su interpretación del párrafo segundo del artículo LVI dejaría el artículo II — que contiene una de las obligaciones fundamentales en el Pacto- en vigor durante el período de un año. La Corte observa, sin embargo, que la interpretación de Colombia privaría tanto al Estado denunciante y, en la medida en que tienen una controversia con el Estado denunciante, a todas las demás partes de acceso a los mismos procedimientos diseñados para dar cumplimiento a esta obligación de recurrir a procedimientos regionales. Como ya se ha explicado anteriormente (véase parágrafo 36 superior), se dice que la interpretación se desprende no de los términos expresados en el segundo párrafo del artículo LVI, sino desde una inferencia que, según Colombia, se debe trazar desde el silencio de ese párrafo respecto a procedimientos instituidos durante el período de un año. La Corte no encuentra una base para sacar de ese silencio una inferencia que no fuese compatible con el objeto y el fin del Pacto de Bogotá.

43. Una parte esencial de la argumentación de Colombia es que su interpretación es necesaria para dar efecto útil al segundo párrafo del artículo LVI. Colombia sostiene que, si el efecto del segundo párrafo se limita a garantizar que los procedimientos iniciados antes de la fecha de envío de la notificación de denuncia pueden continuar después de esa fecha, entonces la disposición es superflua. La regla de que los eventos que ocurren después de la fecha en que se presentó una solicitud no priva a la Corte de su competencia, que existía para esa fecha (véase el parágrafo 33 
supra), garantizaría, en todo caso, que la denuncia del Pacto no afectaría a los procedimientos ya iniciados antes de la denuncia.

La Corte ha reconocido que, en general, la interpretación de un tratado debe buscar dar efecto a cada término en ese tratado, y que ninguna disposición debe interpretarse de una manera que haga que sea carente de significado o efecto - Aplicación de la Convención Internacional sobre la Eliminación de todas las Formas de Discriminación Racial (Georgia c. Federación Rusa), Excepciones preliminares, sentencia, CIJ Reportes 2011 (I), pp. 125-126, párr. 133; Canal de Corfú (Reino Unido c. Albania), Fondo, sentencia, CIJ Reportes 1949, p. 24 - Hay ocasiones, sin embargo, cuando las partes en un tratado adoptan una disposición para que no haya dudas, así tal disposición sea estrictamente necesaria. Por ejemplo, el artículo LVIII del Pacto de Bogotá establece que ciertos tratados interamericanos anteriores dejarán de tener efecto con respecto a las partes en el Pacto tan pronto como el Pacto entre en vigor. El artículo LIX también establece que las disposiciones del artículo LVIII "no se aplicarán a los procedimientos ya iniciados o pactados conforme a alguno de los referidos instrumentos internacionales" de acuerdo con cualquiera de esos tratados anteriores. Si bien ninguna de las partes hizo referencia a estas disposiciones, si se aplica a ellos el enfoque sugerido por Colombia en relación con el artículo LVI, a continuación, el artículo LIX debe considerarse innecesario. Parece ser que las partes en el Pacto de Bogotá consideraron que era conveniente incluir el artículo LIX como resultado de un exceso de precaución. El hecho de que las partes en el Pacto consideraron que la inclusión del artículo LIX sirve a un propósito útil, a pesar de que no era estrictamente necesario, socava el argumento de Colombia de que la disposición similar en el segundo párrafo del artículo LVI no podría haber sido incluida por esa razón.

44. Además, la Corte considera que, al tratar de determinar el sentido del segundo párrafo del artículo LVI, no debería adoptar una interpretación que haga que el primer párrafo de dicho artículo sea carente de significado o efecto. El primer párrafo establece que el pacto se mantendrá en vigor por un período de un año a partir de la notificación de denuncia. La interpretación de Colombia sería, sin embargo, limitar el efecto de esta disposición a los capítulos 1, 6, 7 y 8. El capítulo 8 contiene las disposiciones formales sobre cuestiones tales como la ratificación, entrada en vigor y registro, y no impone obligaciones durante el período posterior a una notificación de denuncia. El capítulo 7 (titulado "Opiniones consultivas") contiene solo un artículo y es puramente permisivo. E1 capítulo 6 también contiene una disposición, que solo requiere que, para 
que una parte recurra al Consejo de Seguridad en relación con la negativa de otra parte de ejecutar una sentencia de la Corte o un laudo arbitral, deberá proponer antes una reunión de consulta de ministros de Relaciones Exteriores de las partes.

El capítulo 1 ("Obligación general de resolver las controversias por medios pacíficos") contiene ocho artículos que imponen obligaciones importantes a las partes, pero, como ya se ha demostrado (véase el parágrafo 42 supra), el artículo II se refiere a la obligación de utilizar los procedimientos del Pacto (ninguno de los cuales estaría disponible durante el período de un año si la interpretación de Colombia fuera aceptada), mientras que los artículos III a VI no tendrían ningún efecto independiente de los procedimientos descritos en los capítulos 2 y 5 . Eso deja solo tres disposiciones teniendo efecto. El artículo I establece que las partes,
"reafirmando solemnemente sus compromisos contraídos por anteriores convenciones y declaraciones internacionales, así como por la Carta de las Naciones Unidas, convienen en abstenerse de la amenaza, del uso de la fuerza o de cualquier otro medio de coacción para el arreglo de sus controversias y en recurrir en todo tiempo a procedimientos pacíficos".

El artículo VII obliga a las partes a no ejercer la protección diplomática con respecto a sus nacionales cuando dichos nacionales hayan tenido a su disposición los medios para presentar sus casos ante los tribunales nacionales competentes. El artículo VIII establece recurrir a los medios pacíficos y no impide recurrir a la autodefensa en el caso de un ataque armado.

La interpretación de Colombia en el segundo párrafo del artículo LVI sería, por lo tanto, limitar la aplicación del párrafo primero del artículo LVI a estas pocas disposiciones.

45. Colombia, basándose en el lenguaje empleado en otros tratados, alega que, si las partes en el Pacto de Bogotá deseaban disponer que los procedimientos iniciados en cualquier momento antes de la expiración del plazo de un año establecido en el primer párrafo del artículo LVI no se viera afectada, fácilmente podrían haber previsto de manera expresa tal efecto. Sin embargo, si, por el contrario, las partes en el Pacto hubiesen pretendido el resultado que alega Colombia, podrían haber hecho, fácilmente, una disposición expresa para tal efecto, pero decidieron no hacerlo. La comparación con los otros tratados no es, por lo tanto, un argumento convincente a favor de la interpretación de Colombia con relación al se- 
gundo párrafo del artículo LVI. Tampoco lo es el hecho de que muchas declaraciones en relación con el artículo 36, párrafo 2, del Estatuto de la Corte se den por terminadas sin previo aviso. Tanto el artículo 36, párrafo 2, del Estatuto como el artículo XXXI del Pacto de Bogotá definen la competencia obligatoria de la Corte. Sin embargo, el artículo 36, párrafo 2, del Estatuto, atribuye la competencia solo entre los Estados que hayan hecho una declaración de reconocimiento de esa jurisdicción. En su declaración en virtud del artículo 36, apartado 2, un Estado es libre de disponer que dicha declaración podrá retirarse con efecto inmediato. Por el contrario, el artículo XXXI del Pacto de Bogotá es un compromiso convencional, que no depende de declaraciones unilaterales para su implementación - Acciones armadas fronterizas y transfronterizas (Nicaragua c. Honduras), Competencia y admisibilidad, sentencia, CIJ Reportes 1988, p. 84, párr. 32-. Las condiciones bajo las cuales un Estado parte en el Pacto puede retirarse de ese compromiso se determinarán en las disposiciones pertinentes del Pacto. El hecho de que muchos Estados opten por presentar sus declaraciones de conformidad con el artículo 36, párrafo 2, de tal manera que puedan poner fin a su aceptación de la jurisdicción de la Corte con efecto inmediato, no arroja luz sobre la interpretación de las disposiciones del Pacto.

46. La Corte ha tomado nota del argumento de Colombia (véase el parágrafo 28) con respecto a la práctica del Estado en la forma de la denuncia del Pacto por El Salvador en 1973 y la propia Colombia en 2012, junto con lo que Colombia describe como la ausencia de cualquier reacción a la notificación de esas denuncias.

Las dos notificaciones de denuncia no se encuentran en los mismos términos. Si bien la notificación de El Salvador declaró que su denuncia "empezará a surtir efecto a partir de hoy", no hay ninguna indicación de qué efecto iba a seguir inmediatamente después de la denuncia. Debido a que el primer párrafo del artículo LVI requiere un preaviso de un año con el fin de dar por terminado el tratado, toda notificación de denuncia comienza a tener efecto inmediato, significando que la transmisión de la notificación hace que el período de un año comience. Por consiguiente, ni la notificación de El Salvador, ni la ausencia de cualquier comentario al respecto por las demás partes en el Pacto, arroja alguna luz sobre la cuestión presentada ante la Corte.

La propia notificación de la denuncia de Colombia especifica que "la denuncia [del Pacto] entra en vigor a partir de hoy con respecto a los procedimientos que se inicien a partir de la presente notificación, de conformidad con el segundo párrafo del artículo LVI". Sin embargo, la Corte 
no puede leer en la ausencia de objeciones por parte de las demás partes en el Pacto con respecto a la notificación de un acuerdo, en el sentido del artículo 31(3)(b) de la Convención de Viena, con respecto a la interpretación de Colombia del artículo LVI. La Corte tampoco considera que la falta de observaciones por parte de Nicaragua ascendió a aquiescencia. El hecho de que Nicaragua inició un procedimiento en el caso relativo a la delimitación de la plataforma continental entre Nicaragua y Colombia más allá de 200 millas náuticas de la costa de Nicaragua (Nicaragua c. Colombia) y en el presente caso, dentro del plazo de un año de la transmisión de la notificación de denuncia de Colombia, refuerza esta conclusión.

47. En cuanto al argumento de Colombia en relación con los travaux préparatoires, la Corte considera que los travaux préparatoires del Pacto demuestran que lo que se hizo fue tomar para el primer párrafo del artículo LVI los términos del artículo $9^{\circ}$ del Tratado General de Arbitraje Interamericano de 1929 y el artículo 16 de la Convención General de Conciliación Interamericana de 1929. El segundo párrafo del artículo LVI se originó de una propuesta de Estados Unidos en 1938, que no tenía contraparte en los Tratados de 1929. Sin embargo, los travaux préparatoires no dan ninguna indicación en cuanto a la finalidad precisa detrás de la adición, de lo que se convirtió en el segundo párrafo del artículo LVI. Así mismo, la Corte observa que, si la opinión de Colombia en cuanto al significado del segundo párrafo fuera correcta, entonces la inserción del nuevo párrafo habría operado para restringir el efecto de la disposición que, incluso antes de que Estados Unidos hiciera su propuesta, las partes contemplaban traer de los Tratados de 1929. Sin embargo, no hay ninguna indicación en ninguna parte de los travaux préparatoires de que alguien considerara que la incorporación de este nuevo párrafo traería consigo un cambio tan importante.

48. Por todas las razones anteriores el tribunal considera que la interpretación de Colombia del artículo LVI no puede ser aceptada. Tomando el artículo LVI en su conjunto, y a la luz de su contexto y el objeto y fin del Pacto, la Corte concluye que el artículo XXXI de atribución de competencia a la Corte se mantuvo en vigor entre las partes en la fecha en que la demanda del presente caso fue interpuesta. La terminación posterior del pacto entre Nicaragua y Colombia no afecta la competencia que existía en la fecha en que se inició el procedimiento. Por lo tanto, la primera excepción preliminar de Colombia debe ser rechazada. 


\section{Segunda excepción preliminar}

49. En su segunda excepción preliminar, Colombia sostiene que con anterioridad a la presentación de la demanda de Nicaragua del 26 de noviembre de 2013 no existía diferendo alguno entre las partes respecto a las pretensiones solicitadas en la demanda que pudiera activar los mecanismos de solución de controversias estipulados en el Pacto de Bogotá, en particular, aquellos relativos a la jurisdicción de la Corte.

50. Según el artículo 38 del Estatuto, la función de la Corte es decidir en concordancia con el derecho internacional las disputas que los Estados le presenten. Por virtud del artículo XXXI del Pacto de Bogotá, los Estados partes acordaron aceptar la jurisdicción obligatoria de la Corte, en conformidad con el artículo 36, parágrafo 2, del Estatuto, para "todas las controversias de orden jurídico que surjan entre ellas".

La existencia de una disputa entre las partes es una condición para la jurisdicción de la Corte. Tal disputa, según lo establecido por las sentencias de la Corte, es "un desacuerdo en un punto de derecho o de hecho, un conflicto de opiniones jurídicas o de los intereses de dos sujetos" - Caso de las concesiones Mavrommatis en Palestina, sentencia 2, 1924, CPI, Serie A, No 2, p. 11; ver también Aplicación de la Convención Internacionalpara la Eliminación de todas las Formas de Discriminación Racial (Georgia c. Federación Rusa), Objeciones preliminares, sentencia, CIJ Reportes 2011 (I), p. 84, para. 30_. "Debe evidenciarse que la pretensión de una parte es efectivamente opuesta a la de la otra" - Casos relativos al África Sudoccidental (Etiopía c. Sudáfrica, Liberia c. Sudáfrica), Objeciones preliminares, sentencia, CIJ Reportes 1962, p. 328 - No importa cuál de ellas solicita una pretensión y cuál se le opone. Lo que importa es que "dos partes sostienen visiones claramente opuestas concernientes al cumplimiento o incumplimiento de ciertas obligaciones internacionales" (Interpretación de los Tratados de Paz con Bulgaria, Hungría y Rumania, primera fase, Opinión Consultiva, CIJ Reportes, 1950, p. 74).

La Corte recuerda que "el que exista una controversia internacional es un asunto de una determinación objetiva" por parte de la Corte - ibid.; ver también Cuestión relativa a la obligación de juzgar y extraditar (Bélgica c. Senegal), sentencia, CIJ Reportes 2012 (ii), p. 442, para. 46; Aplicación de la Convención Internacional para la Eliminación de todas las Formas de Discriminación Racial (Georgia c. Federación Rusa), Objeciones preliminares, sentencia, CIJ Reportes 2011 (I), p. 84, para. 30; Ensayos nucleares (Australia c. Francia), sentencia, CIJ Reportes 1974, p. 476, para. 58-. "La determinación de la Corte debe tornarse en una examinación de los hechos. Es un asunto 
sustancial, no formal" - Aplicación de la Convención Internacional para la Eliminación de todas las Formas de Discriminación Racial (Georgia c. Federación Rusa), Objeciones preliminares, sentencia, CIJ Reportes 2011 (I), p. 84, para. 30-.

51. Según el artículo 40, parágrafo 1, del Estatuto y el artículo 38, parágrafo 2, del Reglamento de la Corte, el demandante debe indicar "el objeto de la disputa" en su demanda, especificando la "naturaleza precisa de la pretensión" — ver Obligación de negociar un acceso al océano Pacífico (Bolivia c. Chile), Objeciones preliminares, sentencia del 24 de septiembre de 2015, para. 25; Jurisdicción de pesquerías (España c. Canadá), Jurisdicción de la Corte, sentencia, CIJ Reportes 1998, p. 448, para. 29-. Aun así, "es la Corte por sí misma [...] quien determina bajo un análisis objetivo la materia de la disputa entre las partes", es decir, "identificar el verdadero asunto en el caso e identificar el objeto de la pretensión" - Ensayos nucleares (Australia c. Francia), sentencia, CIJ Reportes 1974, p. 262, para. 29; Ensayos nucleares (Nueva Zelanda c. Francia), sentencia, CIJ Reportes 1974, p. 466, para. 30; Obligación de negociar un acceso al océano Pacífico (Bolivia c. Chile), Objeciones preliminares, sentencia del 24 de septiembre de 2015, para. 26-.

52. En principio, la fecha crítica para determinar la existencia de una disputa es la fecha en la que la demanda es remitida a la Corte - Aplicación de la Convención Internacional para la Eliminación de todas las Formas de Discriminación Racial (Georgia c. Federación Rusa), Objeciones preliminares, sentencia, CIJ Reportes 2011 (I), p. 84, para. 30; Cuestión de la interpretación y aplicación de la Convención de Montreal de 1971 relativas al incidente aéreo en Lockerbie (Jamabiriya Árabe Libia c. Reino Unido), Objeciones preliminares, sentencia, CIJ Reportes 1998, pp. 25-26, paras. 43-45; Cuestión de la interpretación y aplicación de la Convención de Montreal de 1971 relativas al incidente aéreo en Lockerbie (Jamabiriya Árabe Libia c. Estados Unidos), Objeciones preliminares, sentencia, CIJ Reportes 1998, pp. 130-131, paras. 42-44-.

53. En su demanda, Nicaragua indica que el objeto del diferendo que le presenta a la Corte es el siguiente: "La disputa hace referencia a las violaciones de los derechos soberanos de Nicaragua y las zonas marítimas declaradas por la sentencia de la Corte del 19 de noviembre de 2012 y la amenaza del uso de la fuerza por Colombia para implementar tales violaciones".

En las solicitudes desarrolladas en el memorial (ver parágrafo 12 arriba), Nicaragua solicita a la Corte que determine dos pretensiones principales; una relativa a las presuntas violaciones por parte de Colombia a 
las zonas marítimas de Nicaragua según la delimitación de la Corte en su sentencia de 2012, "como también a los derechos soberanos y a la jurisdicción de Nicaragua en esas zonas", y la otra, concerniente a la presunta violación de Colombia de su obligación de no usar o amenazar con el uso de la fuerza, según el artículo $2^{\circ}$, párrafo 4 , de la Carta de las Naciones Unidas y el derecho internacional consuetudinario.

54. Nicaragua sostiene que, en el período entre la publicación del fallo de 2012 y la fecha de la presentación de su demanda, el 26 de noviembre de 2013, Colombia inicialmente sostuvo que el fallo de 2012 no era aplicable. El 9 de septiembre de 2013, promulgó el Decreto 1946 sobre el establecimiento de una 'zona contigua integral' (en adelante 'Decreto 1946’) que parcialmente se sobrepone con las zonas marítimas que la Corte ha declarado le corresponden a Nicaragua. Adicionalmente, según Nicaragua, Colombia inició un programa de operaciones militares y de vigilancia en esas zonas marítimas. Nicaragua también sostiene que Colombia tomó medidas usando naves militares y aeronaves para intimidar embarcaciones nicaragüenses y que ha continuado con la expedición de licencias autorizando la pesca en esas aguas.

55. Para sostener su segunda objeción preliminar, Colombia sostiene que en ningún momento, hasta la fecha crítica del 26 de noviembre de 2013, fecha en la que Nicaragua presentó su demanda, Nicaragua le indicó a Colombia, por ningún medio, que estaba violando los derechos soberanos y los espacios marítimos declarados por la sentencia de 2012 o que estaba amenazándolo con el uso de la fuerza. Colombia sostiene que Nicaragua no ha elevado ninguna queja ante Colombia, ni de forma escrita u oral, hasta casi diez meses después de que presentó su demanda y tres semanas antes de presentar su memorial, precisamente, mediante una nota diplomática enviada a Colombia el 13 de septiembre de 2014. Colombia sostiene que esta nota "es un esfuerzo evidente de fabricar una disputa donde esta no existe".

56. Colombia sostiene que la demanda de Nicaragua es una "total sorpresa" dada la situación pacífica en el mar y las repetidas declaraciones de las partes de tener la intención de negociar un tratado para implementar la sentencia de 2012. Sostiene Colombia que, antes de la presentación de la demanda, e incluso por un período prolongado después, no existía ninguna disputa sobre las presuntas violaciones de Colombia a los espacios 
marítimos de Nicaragua, o una amenaza de la fuerza que hubiera estado a la base de estas negociaciones.

57. En relación con lo sostenido por Nicaragua en cuanto que Colombia ha repudiado la sentencia de 2012, Colombia sostiene que

"Colombia acepta el fallo de 2012 como obligatorio bajo el derecho internacional. La Corte Constitucional de Colombia tomó la misma posición en su decisión del 2 de mayo de 2014. La pregunta que ha surgido en Colombia es cómo implementar el fallo de 2012 a nivel doméstico, teniendo en cuenta las normas constitucionales relevantes y la naturaleza del sistema jurídico colombiano en materia de fronteras".

Colombia sostiene que, a la luz del artículo 101 de su Constitución, un cambio en las fronteras solo puede ser realizado por la conclusión de un tratado y que Nicaragua ha expresado su voluntad de entrar en negociaciones con Colombia sobre la posibilidad de concluir tal tratado.

58. En relación con el Decreto Presidencial 1946 sobre la 'zona contigua integral', promulgado el 9 de septiembre de 2013 y subsecuentemente enmendado por Decreto 1119 del 17 de junio de 2014, Colombia sostiene que, aunque su propia titularidad a una zona contigua alrededor de sus islas fue plenamente abordada por las partes en el caso concluido con la sentencia de 2012, la delimitación de tal zona no fue un asunto abordado o decidido por la Corte. Colombia señala que, como cualquier otro Estado, tiene derecho a tal espacio marítimo, que es gobernado por el derecho internacional consuetudinario. Indica que su

“zona contigua integral (i) es necesaria para la administración ordenada, control policivo y mantenimiento del orden público en esos espacios marítimos en el Archipiélago de San Andrés, Providencia y Santa Catalina, (ii) que debe ser implementada en conformidad con el derecho internacional y teniendo en consideración derechos de terceros Estados, (iii) está en conformidad con el derecho internacional consuetudinario, y (iv) consecuentemente, no puede sostenerse que sea contraria a la sentencia de la Corte del 19 de noviembre de 2012".

59. Adicionalmente, Colombia sostiene que, bajo el Decreto 1946, su derecho a sancionar violaciones a las leyes y regulaciones concernientes a las materias del decreto solo sería ejercido en relación con actos cometidos 
en sus territorios insulares o su mar territorial, lo que, según Colombia, "corresponde al derecho internacional consuetudinario".

60. Finalmente, Colombia niega que existiera, a la fecha de la presentación de la demanda, cualquier diferendo entre las partes concerniente al uso de la fuerza en el mar, mucho menos una violación del artículo $2^{\circ}$, parágrafo 4, de la Carta de las Naciones Unidas. Sostiene que ha dado instrucciones a sus fuerzas navales de evitar cualquier peligro de confrontación con Nicaragua en el mar. Asevera que, como lo confirman miembros del ejecutivo y Fuerzas Armadas de Nicaragua, "la situación en el Caribe suroccidental es calma, y no han existido problemas".

61. Nicaragua, por su parte, primero señala las declaraciones y afirmaciones de altos mandos colombianos, incluyendo su Jefe de Estado, su Ministra de Relaciones Exteriores y el alto mando de su Fuerza Naval, que, según ella sostiene, indican que Colombia no acepta la delimitación de espacios marítimos según lo determinado por la Corte en su sentencia de 2012. Particularmente se refiere a la declaración hecha el 9 de septiembre de 2013 por el Presidente de Colombia sobre la "estrategia integral de Colombia frente al fallo de la Corte Internacional de Justicia", en la que el Presidente anunció, inter alia, que la sentencia de 2012 no sería aplicada hasta que un tratado se concluyera con Nicaragua. Nicaragua afirma que con la "estrategia integral" y las acciones subsecuentes tomadas bajo la instrucción del Presidente, Colombia endureció su posición de desafío a la sentencia de 2012. Nicaragua sostiene que Colombia no pudo fallar en ver que existía una disputa entre las partes.

62. Nicaragua sostiene que el Decreto 1946 dibuja una zona contigua uniendo las zonas contiguas de todas las islas y cayos de Colombia en el Caribe occidental. Señala que ni el tamaño de la zona contigua, ni la naturaleza de los derechos y la jurisdicción que Colombia clama dentro de ella, son consistentes con la definición de zona contigua reconocida por el derecho internacional. Adicionalmente, según Nicaragua, el Decreto 1946 pretende atribuirle a Colombia espacios marítimos que la Corte determinó en su sentencia de 2012 como correspondientes a Nicaragua. Al proferir el decreto, Nicaragua sostiene que "Colombia transformó en derecho doméstico su rechazo y desafío a la sentencia de 2012” de la Corte.

63. Nicaragua también sostiene que una serie de incidentes que involucran embarcaciones o aeronaves de Colombia ocurrió en el mar. Según 
Nicaragua, un número de estos incidentes tuvo lugar entre la sentencia de 2012 y la fecha de la presentación de la demanda en aguas declaradas por la sentencia de 2012 como nicaragüenses. Indica que las conversaciones entre los comandantes de las fragatas de la Armada Colombiana y agentes de la Guarda Costera de Nicaragua durante tales incidentes demuestran que las partes tenían reclamaciones conflictivas sobre los derechos marítimos en las áreas concernientes.

64. Nicaragua indica que desde que el límite marítimo entre las partes hasta las 200 millas de la costa nicaragüense fue fijado por la Corte, tanto Nicaragua como Colombia, por casi tres años, conocen la extensión geográfica de los derechos marítimos de uno y otro. Según Nicaragua, aun así, después de que la sentencia de 2012 fue proferida, Colombia ha continuado con "reafirmar" su "soberanía" y derechos marítimos en aguas nicaragüenses y ha expedido permisos a sus nacionales para explotar recursos en espacios marítimos nicaragüenses. Nicaragua explica que su propósito al referir hechos que han ocurrido después de la fecha de la presentación de la demanda es demostrar que el problema es continuo.

65. En relación con su alegato relativo a la amenaza del uso de la fuerza por parte de Colombia, Nicaragua sostiene que, además de su afirmación de "soberanía", Colombia ha "acosado" regularmente embarcaciones de pesca nicaragüenses en aguas nicaragüenses, particularmente en la zona conocida como 'Luna Verde', localizada cerca a la intersección del meridiano $82^{\circ}$ con el paralelo $15^{\circ}$, en aguas que la Corte declaró como nicaragüenses. Señala que Colombia lo ha hecho al dirigir fragatas de la naval colombiana a perseguir embarcaciones pesqueras nicaragüenses licenciadas por Nicaragua, como también comandando aeronaves a "acosar" embarcaciones pesqueras nicaragüenses desde el aire.

66. Nicaragua sostiene que ha "constantemente padecido el rechazo de Colombia a cumplir con la sentencia de 2012 y su conducta provocadora dentro de aguas nicaragüenses con paciencia y moderación". Las fuerzas navales nicaragüenses han sido ordenadas a evitar cualquier enfrentamiento con la naval colombiana y, de hecho, han mantenido su distancia de la naval colombiana lo más lejos posible. Nicaragua enfatiza, aun así, que su "posición conciliadora y no escaladora, en ningún momento ha reducido su desacuerdo o anulado la disputa". 
67. La Corte recuerda (ver parágrafo 53) que Nicaragua hace dos solicitudes distintas, una relativa a que Colombia ha violado los derechos soberanos de Nicaragua y sus espacios marítimos, y la otra relativa a que Colombia ha violado su obligación de no usar o amenazar con el uso de la fuerza. La Corte va a examinar estas pretensiones de forma separada para determinar, respecto a cada una de ellas, si existe una disputa dentro del significado establecido en los parágrafos 50 a 52, a la fecha de la presentación de la demanda.

68. La Corte sostiene que, en soporte de sus respectivas posiciones sobre la existencia del diferendo relativo a la primera pretensión de Nicaragua, las partes principalmente se refieren a declaraciones y afirmaciones hechas por los altos representantes de las partes, a la promulgación por Colombia del Decreto 1946 y a los presuntos incidentes en el mar.

69. Considerando, en primer lugar, las declaraciones y afirmaciones de los oficiales de los dos Estados, la Corte observa que, después de la sentencia de 2012, el Presidente de Colombia propuso a Nicaragua negociar un tratado concerniente a los efectos de la sentencia, mientras que el Presidente de Nicaragua, en varias ocasiones, expresó su voluntad de entrar en negociaciones para la conclusión de un tratado para darle efecto a la sentencia y abordar las preocupaciones de Colombia en materia de pesca, protección del medio ambiente y tráfico de drogas. La Corte considera que el hecho de que las partes mantuvieran un diálogo abierto no prueba por sí mismo que, a la fecha de la presentación de la demanda, no existiera entre las partes un diferendo concerniente al objeto de la primera pretensión de Nicaragua.

La Corte nota que Colombia es de la opinión de que sus derechos fueron "infringidos" como resultado de la delimitación marítima de la sentencia de 2012. Tras su reunión con el Presidente de Nicaragua el $1^{\circ}$ de diciembre de 2012, el presidente Juan Manuel Santos de Colombia sostuvo: "Continuaremos — y se lo decimos claro al presidente Ortegabuscando cómo restablecer los derechos que esta sentencia ha infringido gravemente para los colombianos".

Nicaragua, por su parte, insistió que los espacios marítimos declarados por la Corte en su sentencia de 2012 deben ser respetados. El 10 de septiembre de 2013, siguiendo la promulgación por parte de Colombia del Decreto 1946, cuando el presidente Santos reiteró la posición de Colombia sobre la implementación de la sentencia de 2012, el presidente Daniel Ortega sostuvo: 


\begin{abstract}
"Entendemos la posición tomada por el presidente Santos, pero no podemos decir que estamos de acuerdo [...] nosotros aceptamos que es necesario el diálogo, aceptamos que es necesario llegar a cierto tipo de acuerdo, tratado, como sea que quieran llamarlo, para poner en práctica de una forma armónica la sentencia de la Corte Internacional de Justicia”.
\end{abstract}

Es claro a partir de estas declaraciones que las partes sostenían posiciones opuestas sobre la cuestión de sus respectivos derechos en los espacios marítimos cubiertos por la sentencia de 2012.

70. En relación con la proclamación de la 'zona contigua integral', la Corte nota que las partes tienen diferentes posiciones sobre las implicaciones legales de tal acción en el derecho internacional. Mientras Colombia sostiene que tiene derecho a una zona contigua tal como la define el Decreto 1946 bajo el derecho consuetudinario, Nicaragua sostiene que el Decreto 1946 viola sus "derechos soberanos y sus espacios marítimos”, según fueron adjudicados por la Corte en la sentencia de 2012.

71. En relación con los incidentes en el mar que presuntamente tuvieron lugar antes de la fecha crítica, la Corte considera que, aunque Colombia rechaza la caracterización de Nicaragua a lo ocurrido en el mar "como incidentes", esto no refuta el alegato de Nicaragua de que Colombia siga ejerciendo jurisdicción en espacios marítimos que Nicaragua reclama como propios basada en la sentencia de 2012.

72. En lo concerniente al argumento de Colombia de que Nicaragua no presentó ninguna queja sobre las presuntas violaciones de Colombia mediante canales diplomáticos hasta mucho después de presentada la demanda, la Corte considera que, aunque una protesta formal puede ser un paso importante para llamar la atención de la queja de una parte frente a la otra, esta presentación formal no es una condición necesaria. Como lo sostuvo la Corte en el caso concerniente a la Aplicación de la Convención Internacional para la Eliminación de todas las Formas de Discriminación Racial (Georgia c. Federación Rusa), al determinar la existencia o no de una disputa, "el asunto es de fondo, no de forma" —Objeciones preliminares, sentencia, CIJ Reportes 2011 (I), p. 84, para. 30-.

73. La Corte nota que, aunque Nicaragua no envió a Colombia su nota diplomática formal de protesta a las alegadas violaciones, presentadas en forma tardía, de sus derechos marítimos hasta el 13 de septiembre de 2014, casi diez meses después de haber presentado su demanda, en las circunstancias específicas del presente caso, la evidencia claramente 
muestra que, para el momento en el que fue presentada la demanda, Colombia conocía que su promulgación del Decreto 1946 y su conducta en las áreas marítimas declaradas por la sentencia de 2012 como de pertenencia nicaragüense era efectivamente rechazada por Nicaragua. Dadas las declaraciones públicas realizadas por los altos representantes de las partes, como aquellas referidas en el parágrafo 69, Colombia no pudo haber malentendido la posición de Nicaragua sobre tales diferencias.

74. Basada en la evidencia examinada anteriormente, la Corte encuentra que, a la fecha de la presentación de la demanda, existía una disputa concerniente a las presuntas violaciones por Colombia de espacios marítimos de Nicaragua que, según Nicaragua, le habían sido otorgados en la sentencia de 2012.

75. La Corte ahora se enfoca en la cuestión de la existencia de una disputa en relación con la segunda pretensión de Nicaragua, sobre que Colombia, con su conducta, ha violado sus obligaciones de no usar o amenazar con el uso de la fuerza, según el artículo $2^{\circ}$, parágrafo 4 , de la Carta de las Naciones Unidas y el derecho internacional consuetudinario.

76. Aunque Nicaragua hace referencia a un número de incidentes que presuntamente ocurrieron en el mar, la Corte observa que, en relación con aquellos que supuestamente sucedieron antes de la fecha crítica, nada en la evidencia sugiere lo que Nicaragua ha indicado sobre que Colombia ha violado sus obligaciones bajo el artículo $2^{\circ}$, parágrafo 4 , de la Carta de las Naciones Unidas. Por el contrario, miembros del ejecutivo nicaragüense y sus autoridades militares confirman que la situación en el mar es calma y estable. El 14 de agosto de 2013, en la ocasión del $33^{\circ}$ aniversario de las Fuerzas Armadas nicaragüenses, el Presidente de Nicaragua sostuvo:

"Nosotros debemos reconocer que en medio de esta turbulencia mediática, la Fuerza Naval de Colombia, que es muy poderosa y que tiene un gran poder militar, ha sido muy cuidadosa, respetuosa y no ha habido ningún tipo de confrontación entre las armadas de Colombia y de Nicaragua".

El 18 de noviembre de 2013, el comandante de la Fuerza Naval nicaragüense afirmó: "En un año de estar allí no hemos tenido problemas con la Armada colombiana", y que las fuerzas de ambos países "mantuvieron comunicación continua" y no "hubo ningún conflicto en esas aguas".

77. Adicionalmente, la Corte observa que los presuntos incidentes que se dijo ocurrieron antes de que Nicaragua presentara su demanda 
corresponden a la primera pretensión de Nicaragua, más que a la pretensión concerniente a la amenaza del uso de la fuerza de acuerdo con el artículo $2^{\circ}$, parágrafo 4 , de la Carta de las Naciones Unidas y el derecho internacional consuetudinario.

78. De acuerdo con estos hechos, la Corte considera que, a la fecha en la que se presentó la demanda, el diferendo que existía entre Colombia y Nicaragua no podía ser considerado como relativo a posibles violaciones de Colombia al artículo $2^{\circ}$, parágrafo 4 , de la Carta de las Naciones Unidas y el derecho internacional, en el sentido de la prohibición del uso o la amenaza del uso de la fuerza.

79. A la luz de las anteriores consideraciones, la Corte concluye que, a la fecha en que Nicaragua presentó su demanda, existía una disputa concerniente a las presuntas violaciones de Colombia de los derechos y espacios marítimos de Nicaragua, que, según Nicaragua, la Corte había declarado en su sentencia de 2012 como nicaragüenses. Consecuentemente, la segunda objeción preliminar de Colombia debe ser rechazada en cuanto a la primera pretensión de Nicaragua y aceptada frente a la segunda pretensión de Nicaragua.

\section{Tercera excepción preliminar}

80. En su tercera objeción preliminar, Colombia sostiene que la Corte carece de jurisdicción en tanto el artículo II del Pacto de Bogotá impone una condición previa al recurso de los Estados partes a la solución judicial que no ha sido agotada por Nicaragua a la fecha de presentar su demanda.

81. El artículo II del Pacto de Bogotá, que ha sido citado en el parágrafo 41, dicta lo siguiente:

\footnotetext{
"Las altas partes contratantes reconocen la obligación de resolver las controversias internacionales por los procedimientos pacíficos regionales antes de llevarlas al Consejo de Seguridad de las Naciones Unidas. En consecuencia, en caso de que entre dos o más Estados signatarios se suscite una controversia que, en opinión de las partes, no pueda ser resuelta por negociaciones directas a través de los medios diplomáticos usuales, las partes se comprometen a hacer uso de los procedimientos establecidos en este tratado en la forma y condiciones previstas en los artículos siguientes, o bien de los procedimientos especiales que, a su juicio, les permitan llegar a una solución”.
} 
82. Refiriéndose a la sentencia de 1988 en el caso Actividades armadas fronterizas y transfronterizas (Nicaragua c. Honduras) (en adelante la sentencia de 1988), Colombia sostiene que el recurrir a procedimientos pacíficos del Pacto cumpliría con el artículo II del Pacto solo si un intento de negociar una solución ha sido realizado de buena fe, y está claro, tras esfuerzos razonables, que un punto muerto ha sido alcanzado y que no hay probabilidad de resolver el diferendo por tales medios. Colombia señala, de forma contraria a Nicaragua, que el término "en opinión de las partes" en el artículo II refiere a la opinión de ambas partes, como lo dicen las versiones en inglés, portugués y español del Pacto, y no a la opinión de solo una de las partes. Colombia indica que, basada en su conducta y en la de Nicaragua, no puede concluirse que la presunta controversia, en la opinión de las partes, no pueda ser resuelta por negociación directa mediante los canales diplomáticos convencionales al momento de la presentación de Nicaragua de su demanda.

83. Colombia sostiene que el hecho de que las partes han entrado en diálogo sobre la posibilidad de negociar un tratado para implementar la sentencia de 2012 indica que los dos lados se mantienen con la voluntad de resolver sus diferencias mediante negociaciones directas. Para demostrar tal intención por parte de Nicaragua, Colombia en sus presentaciones escritas se refiere a un número de declaraciones y afirmaciones hechas por el Presidente de Nicaragua en la materia.

84. Colombia señala que, incluso después de presentar su demanda, se reportó que el Presidente de Nicaragua, en varias ocasiones, seguía hablando de firmar acuerdos con Colombia y propuso establecer una comisión binacional para coordinar las operaciones de pesca, patrullaje antidrogas y la administración conjunta de la Reserva de Biosfera Marina del Seaflower en el mar Caribe, basados en la delimitación de la Corte.

85. Colombia indica que el comandante de la Fuerza Naval nicaragüense y el comandante del Ejército nicaragüense sostuvieron la misma opinión con relación a la paz y la estabilidad de las aguas concernientes. Este hecho confirma, según Colombia, que hasta la presentación de la demanda Nicaragua tenía la opinión de que los dos vecinos marítimos sostenían buenas relaciones, que no había 'incidentes' navales y que podían resolver las diferencias mediante negociaciones. Colombia señala que la presentación de la demanda de Nicaragua "se opone completamente a la realidad".

86. Colombia sostiene que también mantuvo la opinión de que los asuntos marítimos entre las partes resultantes de la sentencia de 2012 
podían ser resueltos por negociación directa. Indica que Nicaragua infirió incorrectamente de la declaración del Presidente colombiano el 19 de noviembre de 2012 que Colombia rechazaba la sentencia de 2012. Colombia señala que, por instrucción de su Presidente, su Ministra de Relaciones Exteriores había iniciado conversaciones con su homólogo nicaragüense el 20 de noviembre de 2012. Posteriormente, refiere las declaraciones de su Ministra de Relaciones Exteriores el 14 de septiembre de 2013, donde ella reiteró que "Colombia se encuentra abierta al diálogo con Nicaragua para firmar un tratado que establezca los límites y el régimen legal que contribuya a la seguridad y estabilidad de la región".

87. Colombia explica que la protección de los derechos históricos de pesca de la población del Archipiélago de San Andrés, Providencia y Santa Catalina son de la mayor importancia para el país. Sostiene que las declaraciones hechas por las más altas autoridades de Colombia con la lectura de la sentencia de 2012 deben ser entendidas en un contexto que, contrario a lo que Nicaragua busca presentar, no implican en ningún caso un desconocimiento de la sentencia de la Corte. Colombia señala que la fecha de la demanda de Nicaragua no se dio por la inutilidad de las negociaciones, sino por el hecho de que el Pacto de Bogotá estaba próximo a dejar de estar en vigor entre las partes.

88. Por su parte, Nicaragua rechaza la interpretación del artículo II hecha por Colombia, sosteniendo que Colombia malinterpreta la sentencia de la Corte de 1988. Indica que la Corte, en esta sentencia, explícitamente declinó aplicar la jurisprudencia relativa a cláusulas compromisorias en otros tratados, pero se refirió a la opinión de las partes con relación a la posibilidad de un acuerdo negociado en los términos del artículo II. Basándose en la versión en francés del Pacto, Nicaragua sostiene que el artículo II del Pacto requiere que la Corte determine cuándo, desde un punto de vista objetivo, una de las partes es de la opinión de que la disputa no puede ser resuelta por negociación directa.

89. Nicaragua sostiene que la presente disputa surge de las acciones de Colombia subsecuentes a la sentencia de 2012. Primero, Colombia al desconocer la sentencia de 2012; posteriormente, afirmando nuevas pretensiones sobre aguas ya adjudicadas por la Corte como nicaragüenses, y ejerciendo supuestos derechos soberanos y jurisdicción en esas aguas. Según Nicaragua, los eventos que ocurrieron en los dos meses y medio 
hasta la presentación de la demanda demuestran que las partes eran de la opinión de que su disputa concerniente a las violaciones de Colombia a los derechos soberanos y espacios marítimos de Nicaragua no podía ser resuelta por medios de negociación directa. Resalta que tres días después de la promulgación del Decreto 1946, el presidente Juan Manuel Santos le solicitó a la Corte Constitucional colombiana que declarara los artículos XXXI y L del Pacto de Bogotá como inconstitucionales, pues, a su parecer, la Constitución colombiana solo permite que los límites y fronteras nacionales sean modificados mediante un tratado debidamente ratificado.

Nicaragua indica que el Presidente de Colombia también declaró que, sin un tratado con Nicaragua, Colombia continuaría "ejerciendo soberanía hasta el meridiano 82", que históricamente ha reclamado como frontera marítima, a pesar de la sentencia de 2012.

90. Frente a las referencias de Colombia a la declaración de su Ministra de Relaciones Exteriores en cuanto a que su país estaba abierto al diálogo (ver parágrafo 86), Nicaragua señala que, adicionalmente a esos comentarios, la Ministra agregó que el gobierno de Colombia "aguarda la decisión de la Corte Constitucional antes de comenzar cualquier acción”. Nicaragua sostiene que, basado en tales declaraciones y afirmaciones, es evidente para Nicaragua que Colombia era de la opinión de que ninguna negociación era posible entre las partes para resolver la disputa relativa a las violaciones de Colombia a los derechos soberanos y espacios marítimos de Nicaragua a la fecha de la presentación de la demanda.

91. Nicaragua, al reiterar su voluntariedad a negociar un tratado con Colombia para la implementación de la sentencia de 2012, enfatiza que la materia de las negociaciones entre las partes se encuentra totalmente desligada de la materia en disputa en el presente caso. Sostiene que Colombia en sus objeciones preliminares ha "cuidadosamente elegido evadir las diferencias críticas" entre los dos temas. Nicaragua señala que ha estado dispuesta a discutir con Colombia los arreglos en materia de pesca, protección ambiental de la Reserva de Biosfera Marina del Seaflower y la lucha contra el tráfico de droga en el mar Caribe, pero "de ninguna manera está dispuesta a ceder los límites marítimos que la Corte ha formulado" entre las partes.

92. La Corte recuerda que en su sentencia de 1988 decidió que, para el propósito de determinar la aplicación del artículo II del Pacto, no 
estaba "obligada por la mera afirmación de una u otra parte de que su opinión tenía cierto efecto". La Corte enfatizó que "debe, en el ejercicio de su función judicial, ser libre de efectuar su propia determinación sobre la cuestión basada en la evidencia disponible" - Actividades armadas fronterizas y transfronterizas (Nicaragua c. Honduras), Jurisdicción y admisibilidad, sentencia, CIJ Reportes 1988, p. 95, para. 65-.

93. La Corte estableció claramente que las partes deben proveer evidencia sustantiva para demostrar que ellas consideraron de buena fe que la disputa podía o no podía ser resuelta por negociaciones directas mediante los canales diplomáticos habituales. La fecha crítica en la que "la opinión de las partes" debe ser establecida para la aplicación del artículo II del Pacto es la fecha en la que se instituyen los procedimientos.

94. Adicionalmente, en su sentencia de 1988, la Corte tomó nota de la discrepancia entre el texto en francés y los otros tres idiomas oficiales del texto (inglés, portugués y español) del artículo II; el primero se refiere a la opinión de una de las partes ("de l'avis de l'une des parties"), mientras los otros se refieren a la opinión de ambas partes. La Corte, en todo caso, no estimó necesario resolver el problema presentado por la discrepancia textual antes de considerar la aplicación del artículo II en ese caso. Procedió basándose en que consideraría si esa opinión de las partes se refería a si era posible o no resolver la disputa por negociación, dependiendo de la evidencia presentada por las partes.

95. En el presente caso, como en la sentencia de 1988, no será necesario para la Corte reconstruir los argumentos presentados por las partes en relación con la interpretación del término "en la opinión de las partes" ("de l'avis de l'une des parties") en el artículo II del Pacto. La Corte comenzará por determinar si la evidencia presentada demuestra que, a la fecha de la presentación de la demanda de Nicaragua, ninguna de las partes podía plausiblemente mantener que la disputa entre ellas podía ser resuelta por negociación directa a través de los canales diplomáticos usuales. (Ver, al respecto, ibid., p. 99, para. 75).

96. La Corte recuerda que las afirmaciones y declaraciones referidas por las partes en sus presentaciones orales y escritas son todas producidas por las más altas autoridades de los dos Estados. Como la Corte indicó en el caso Georgia c. Federación Rusa:

"En general, en el derecho y la práctica internacional, es el ejecutivo del Estado quien representa al Estado en sus relaciones internacionales y habla por él en el nivel internacional. — Actividades armadas en el territo- 
rio del Congo (Nueva demanda; 2002) (República Democrática del Congo c. Ruanda), Jurisdicción y admisibilidad, sentencia, CIJ Reportes 2006, p. 27, paras. 46-47—. Así, principal atención se le dará a las declaraciones hechas por o apoyadas por los ejecutivos de los dos Estados. - Aplicación de la Convención Internacional para la Eliminación de todas las Formas de Discriminación Racial (Georgia c. Federación Rusa), Objeciones preliminares, sentencia, CIJ Reportes 2011 (I), p. 87, para. 37”-

La Corte, por lo tanto, considera que, al determinar las posiciones de las partes en relación con la posibilidad de una solución negociada, debe centrarse en esas declaraciones y afirmaciones para obtener sus conclusiones.

97. La Corte observa que, a través de varias comunicaciones entre los jefes de Estado de ambos países desde la sentencia de 2012, cada parte ha indicado que estaba abierta al diálogo para tratar varios asuntos elevados por Colombia como resultado de la sentencia.

El Presidente de Nicaragua expresó la voluntad de Nicaragua de negociar un tratado o acuerdo con Colombia para así facilitar los requisitos domésticos de esta, bajo su derecho nacional, para la implementación de la sentencia. Los asuntos que las partes identificaron para un posible diálogo incluyen actividades de pesca para los habitantes de San Andrés, Providencia y Santa Catalina en aguas que han sido reconocidas como nicaragüenses para la Corte, la protección de la Reserva de Biosfera Marina del Seaflower y la lucha contra el tráfico de drogas en el mar Caribe.

98. La Corte anota, sin embargo, que las materias mencionadas anteriormente para negociación son diferentes a la materia de la disputa entre las partes. Según Nicaragua, las negociaciones entre las partes debieron haber sido conducidas desde la perspectiva de un posible tratado que no afectará los espacios marítimos declarados por la sentencia de 2012. En otras palabras, para Nicaragua, tales negociaciones debían estar restringidas a las modalidades y mecanismos de implementación de dicha sentencia.

Colombia no definió la materia de las negociaciones de esa manera. En palabras de su Ministra de Relaciones Exteriores, pretende "firmar un tratado que establezca los límites y un régimen legal que contribuya a la seguridad y estabilidad de la región".

99. La Corte considera que el argumento de Colombia de que las partes se mantuvieron abiertas al diálogo, por lo menos hasta la fecha de la presentación de la demanda, no es un factor decisivo, porque lo que es esencial para la Corte es decidir si sí o no, a la fecha, dadas las posiciones y conductas de las partes frente a las supuestas violaciones de Colombia a 
los derechos soberanos y espacios marítimos de Nicaragua según la delimitación de la sentencia de 2012, las partes consideraban de buena fe que alguna posibilidad de una solución negociada existía o no.

100. La Corte nota que las partes no contestan el hecho de que la situación en el mar sea "tranquila" y "estable" durante el período relevante. Ese hecho, en todo caso, no es necesariamente indicativo de que, en opinión de las partes, la disputa en el presente caso sí pudiera ser resuelta mediante negociaciones. Desde el inicio de los eventos posteriores a la sentencia de 2012, Nicaragua se opuso firmemente a la conducta de Colombia en las áreas que la sentencia de 2012 había declarado como pertenecientes a Nicaragua. La posición de Colombia sobre la negociación de un tratado fue igualmente firme durante todo el curso de las comunicaciones con Nicaragua. Ninguna evidencia enviada a la Corte indica que, a la fecha de la demanda de Nicaragua, las partes hubieran contemplado, o estuvieran en la posición de, mantener negociaciones para resolver la disputa concerniente a las presuntas violaciones de Colombia a los espacios marítimos de Nicaragua y sus derechos soberanos, que, según Nicaragua, fueron declarados como nicaragüenses por la sentencia de 2012.

101. Dadas las anteriores consideraciones, la Corte concluye que, a la fecha de la presentación de la demanda de Nicaragua, la condición del artículo II se había cumplido. Por lo tanto, la tercera objeción preliminar de Colombia debe ser rechazada.

\section{Cuarta excepción preliminar}

102. Nicaragua sostiene que existen dos fuentes de competencia de la Corte. En el caso de que la Corte no encuentre su jurisdicción a la luz del artículo XXXI del Pacto de Bogotá, tiene jurisdicción bajo "su poder inherente de pronunciarse sobre acciones requeridas por su sentencia". En su cuarta objeción preliminar, Colombia señala que la Corte no tiene tal "jurisdicción inherente" sobre la que Nicaragua pueda sustentar su posición.

103. Colombia indica que la argumentación de Nicaragua sobre "jurisdicción inherente" no encuentra soporte ni en el Estatuto de la Corte ni en sus reglas jurisprudenciales. Sostiene que, si la posición de Nicaragua se tomara en serio, se afectaría la base de jurisdicción consensual bajo el artículo 36 del Estatuto de la Corte. En tanto que la teoría de Nicaragua de una "jurisdicción inherente" ignora todas las condiciones que los Estados han puesto de presente para aceptar la jurisdicción. Señala que, en vez de aplicar las reglas y práctica de la Corte, Nicaragua se refiere a las reglas y 
la práctica de la Corte Europea de Derechos Humanos, así como a la de la Corte Interamericana de Derechos Humanos; al hacerlo, Nicaragua ignora la autorización estatutaria explícita dada a esas cortes para monitorear la implementación de sus decisiones.

104. La Corte nota que la "jurisdicción inherente" argumentada por Nicaragua es una pretensión alternativa que invoca para el establecimiento de la jurisdicción de la Corte en el presente caso. El argumento de Nicaragua, en cualquier caso, solo puede aplicar a la disputa que existía al momento de la presentación de la demanda. En tanto la Corte ha encontrado su jurisdicción en relación con esa disputa bajo el artículo XXXI del Pacto de Bogotá, considera que no hay necesidad de pronunciarse sobre la pretensión de Nicaragua sobre "jurisdicción inherente" y, por lo tanto, no tomará ninguna posición respecto de ella. Consecuentemente, no hay necesidad de que la Corte se pronuncie sobre la cuarta excepción preliminar de Colombia.

\section{Quinta excepción preliminar}

105. La quinta objeción preliminar a la presente demanda consiste en considerarla como un intento de ejecución de la sentencia de 2012 aunque la Corte no tenga jurisdicción posadjudicativa en materia de implementación. Colombia sostiene que la Carta de las Naciones Unidas y el Estatuto de la Corte se encuentran basados en una división de funciones según las cuales a la Corte se le confiere la tarea de adjudicar, mientras que la implementación posjudicial se le reserva al Consejo de Seguridad en concordancia del parágrafo 2 del artículo 94 de la Carta, que indica:

\footnotetext{
"Si una de las partes en un litigio dejare de cumplir las obligaciones que le imponga un fallo de la Corte, la otra parte podrá recurrir al Consejo de Seguridad, el cual podrá, si lo cree necesario, hacer recomendaciones o dictar medidas con el objeto de que se cumpla la ejecución del fallo”.
}

Según Colombia, la misma división de funciones es reconocida por el Pacto de Bogotá, que en su artículo L señala: 
"Si una de las altas partes contratantes dejare de cumplir las obligaciones que le imponga un fallo de la Corte Internacional de Justicia o un laudo arbitral, la otra u otras partes interesadas, antes de recurrir al Consejo de Seguridad de las Naciones Unidas, promoverá una reunión de consulta de Ministros de Relaciones Exteriores a fin de que acuerde las medidas que convenga tomar para que se ejecute la decisión judicial o arbitral".

La posición de Colombia es que al fondo de la demanda de Nicaragua existe una alegación de que Colombia está incumpliendo la sentencia de 2012 y que Nicaragua pretende el derecho a obtener una subsecuente ejecución de la implementación de la sentencia.

106. Nicaragua niega que su demanda en los presentes procedimientos represente un intento de obtener medidas de ejecución posjudiciales. Sostiene que la materia de su demanda es la violación por parte de Colombia de los derechos soberanos y espacios marítimos adjudicados a Nicaragua por la Corte en 2012. Nicaragua rechaza el análisis de Colombia del artículo 92, parágrafo 2, de la Carta de las Naciones Unidas y el artículo L del Pacto de Bogotá. Según Nicaragua, ninguna de esas provisiones opera de tal manera que pueda precluir la jurisdicción inherente de la Corte (ver parágrafos 102 a 104) o la jurisdicción conferida en el artículo XXXI del Pacto de Bogotá.

107. La quinta objeción preliminar de Colombia está dirigida al argumento alternativo de Nicaragua de que la Corte tiene jurisdicción inherente en relación con el presente caso. Colombia sostiene que, aunque la Corte encontrará — contrario a su cuarta objeción preliminar- que posee jurisdicción inherente, tal jurisdicción inherente no implica un poder de jurisdicción para la ejecución posjudicial.

La Corte ya ha decidido que no necesita determinar si posee una jurisdicción inherente, en tanto encuentra su jurisdicción en el artículo XXXI del Pacto de Bogotá (ver parágrafo 104). Consecuentemente, es innecesario pronunciarse sobre la quinta objeción preliminar de Colombia en cuanto a la jurisdicción inherente. 
108. En todo caso, Colombia indica en sus argumentos que su quinta excepción preliminar también fue elevada como objeción a la jurisdicción de la Corte bajo el artículo XXXI del Pacto de Bogotá. Colombia sostiene que "incluso asumiendo que [...] la Corte tenga jurisdicción en este caso a la luz del artículo XXXI del Pacto de Bogotá, tal jurisdicción no puede extenderse a las pretensiones de Nicaragua de una ejecución por parte de la Corte basada en un presunto incumplimiento de Colombia de la sentencia de 2012".

En tanto la Corte ha concluido que tiene jurisdicción bajo el artículo XXXI del Pacto, la quinta objeción preliminar debe abordarse en lo que refiera a la jurisdicción del Pacto de Bogotá.

109. La quinta objeción preliminar de Colombia descansa en la premisa de que la Corte está siendo llamada a ejecutar la sentencia de 2012. La Corte concuerda con Colombia en que es la Corte, no Nicaragua, quien decide el carácter real del diferendo ante ella (ver parágrafo 51). Aun así, como la Corte decidió (ver parágrafo 79), la disputa ante ella en los presentes procedimientos concierne a las alegadas violaciones por Colombia a los derechos de Nicaragua en los espacios marítimos que, de acuerdo con Nicaragua le fueron adjudicados en la sentencia de 2012. En lo que corresponde a Nicaragua y Colombia, esos derechos se derivan del derecho consuetudinario. La sentencia de 2012 es sin duda relevante para la disputa en tanto determina el límite marítimo entre las partes y, consecuentemente, cuál de las partes posee derechos soberanos bajo el derecho consuetudinario en los espacios marítimos a los que se refiere el caso. Aun así, en el presente caso, Nicaragua solicita a la Corte que juzgue y declare que Colombia ha incumplido "su obligación de no violar los espacios marítimos según lo delimitado en el parágrafo 251 de la sentencia del 19 de noviembre de 2012, como los derechos soberanos de Nicaragua y su jurisdicción en tales espacios" y "que, consecuentemente, Colombia tiene la obligación de retrotraer las consecuencias legales y materiales de sus hechos internacionalmente ilícitos, y dar reparación integral por el daño causado por tales hechos" (parágrafo 12). Nicaragua no busca la ejecución de la sentencia de 2012 en sí misma. La Corte no está, por lo tanto, siendo llamada a tomar los roles respectivos de la reunión de consulta de Ministros de Relaciones Exteriores (artículo L del Pacto de Bogotá) o del Consejo de Seguridad (artículo 94, parágrafo 2, de la Carta de las Naciones Unidas).

110. La quinta excepción preliminar de Colombia debe ser por ello rechazada. 
111. Por estas razones,

la Corte,

1) (a) unánimemente,

rechaza la primera objeción preliminar elevada por la República de Colombia;

(b) por quince a uno,

rechaza la segunda objeción preliminar elevada por la República de Colombia en lo concerniente a la existencia de una disputa relativa a las presuntas violaciones por Colombia de los derechos soberanos y espacios marítimos que, según Nicaragua, la sentencia de 2012 declaró que le pertenecían.

A favor: presidente Abraham; vicepresidente Yusuf; jueces Owada, Tomka, Bennouna, Cançado Trindade, Greenwood, Xue, Donoghue, Gaja, Sebutinde, Bhandari, Robinson, Gevorgian, juez ad hoc Daudet,

En contra: juez ad hoc Caron;

(c) unánimemente,

acepta la segunda objeción preliminar elevada por la República de Colombia en lo concerniente a la existencia de una disputa relativa a la supuesta violación por Colombia de su obligación de no usar o amenazar con el uso de la fuerza;

(d) por quince votos a uno,

rechaza la tercera objeción preliminar elevada por la República de Colombia;

A favor: presidente Abraham; vicepresidente Yusuf; jueces Owada, Tomka, Bennouna, Cançado Trindade, Greenwood, Xue, Donoghue, Gaja, Sebutinde, Bhandari, Robinson, Gevorgian, juez ad hoc Daudet,

En contra: juez ad hoc Caron;

(e) unánimemente,

encuentra que no hay bases para pronunciarse sobre la cuarta excepción preliminar elevada por la República de Colombia;

(f) por quince votos contra uno,

rechaza la quinta objeción preliminar elevada por la República de Colombia; 
A favor: presidente Abraham; vicepresidente Yusuf; jueces Owada, Tomka, Bennouna, Cançado Trindade, Greenwood, Xue, Donoghue, Gaja, Sebutinde, Robinson, Gevorgian, jueces ad hoc Daudet, Caron;

En contra: juez Bhandari;

(2) por catorce votos contra dos,

encuentra que tiene jurisdicción, según el artículo XXXI del Pacto de Bogotá, para pronunciarse sobre la disputa entre la República de Nicaragua y la República de Colombia referida en el subparágrafo (b) arriba.

A favor: presidente Abraham; vicepresidente Yusuf; jueces Owada, Tomka, Bennouna, Cançado Trindade, Greenwood, Xue, Donoghue, Gaja, Sebutinde, Caron, Robinson, Gevorgian, juez ad hoc Daudet,

En contra: juez Bhandari, juez ad hoc Caron.

Hecho en inglés y francés, siendo el texto en inglés el que hace fe. En el Palacio de la Paz, La Haya, el 17 de marzo de dos mil dieciséis, en tres copias, una que será puesta en los archivos de la Corte, y las otras transmitidas a los gobiernos de la República de Nicaragua y la República de Colombia, respectivamente.

$$
\begin{array}{r}
\text { (Firmada) Ronny Abraham, } \\
\text { Presidente }
\end{array}
$$

El juez Cançado Trindade anexa su opinión separada a la sentencia de la Corte; el juez Bhandari anexa su declaración a la sentencia de la Corte; el juez ad hoc Caron anexa su opinión disidente a la SENTENCIA de la Corte.

Iniciales R. A. Iniciales $\mathrm{Ph}$. C. 


\section{Traducción de los resúmenes de las opiniones de los jueces preparados por la Secretaría de la Corte Internacional de Justicia}

\section{Opinión separada del juez Cançado Trindade}

1. En su opinión separada, compuesta por once partes, el juez Cançado Trindade presenta los fundamentos de su posición personal sobre una cuestión planteada por las partes contendientes, Nicaragua y Colombia, ante la Corte Internacional de Justicia (CIJ), en el transcurso del presente caso de Presunta violación de derechos soberanos y espacios maritimos en el mar Caribe (fases escrita y oral). La cuestión relativa a la cuarta excepción preliminar planteada por Colombia se refiere a las facultades inherentes de los tribunales internacionales contemporáneos, cuya jurisprudencia fue invocada por ambas partes en litigio ante la CIJ.

2. El juez Cançado Trindade comienza observando (parte I) que, en la presente sentencia, la CIJ, habiendo constatado que tiene jurisdicción bajo el Pacto de Bogotá, desestimando la primera excepción preliminar de Colombia, pudo y debería haber arrojado alguna luz sobre los puntos en la cuestión formulada por las partes contendientes - la alegación de Nicaragua de "jurisdicción inherente" y la cuarta excepción preliminar de Colombia-, aunque fuese rechazar esta también, en lugar de decir que "no hay fundamento" para tratar la cuestión (párrafo 104 de la sentencia).

3. Dada la importancia que él atribuye a esta cuestión particular, recurrente en la práctica de los tribunales internacionales, y dado que se le señaló a la CIJ en el presente caso, se sintió obligado a dejar en los registros, en primer lugar, las posiciones de las partes y el trato que se les dispensa (partes II-III), y, sucesivamente, los fundamentos de su propia posición personal sobre esto, en sus aspectos interrelacionados (partes IV-X), a saber: a) poderes inherentes más allá del consentimiento estatal; b) la interpretación teleológica (ut res magis valeat quam pereat) más allá del consentimiento estatal; c) la competencia de la competencia / Kompetenz Kompetenz más allá del consentimiento estatal; d) recta ratio por encima de la voluntas, conciencia humana por encima de la 'voluntad'; e) poderes inherentes para superar las lacunae, y la relevancia de los principios generales; 
f) poderes inherentes y juris dictio, más allá de la justicia transaccional; y g) poderes inherentes y supervisión del cumplimiento de las sentencias.

4. El juez Cançado Trindade sostiene que se trata de un asunto que no puede ser simplemente eludido, pues es "pertinente para el funcionamiento de los tribunales internacionales contemporáneos, en su misión común de realización de la justicia" (parágrafo 4). Después de recordar las comunicaciones escritas de ambas partes, así como las respuestas dadas por Nicaragua y Colombia a las tres preguntas que hizo a ambas en la sesión pública del Tribunal de Justicia del 02.10.2015 (parágrafos 5-12). Él señala el alcance más amplio de las competencias inherentes sostenidas por Nicaragua (parágrafo 13). La CIJ, a su juicio, debería haberse pronunciado sobre el tema (en sus distintas perspectivas), en lugar de haberse "abstenido de hacerlo" en una perspectiva "más bien minimalista" — que no comparte- del ejercicio de la función judicial internacional (parágrafo 15).

5. El juez Cançado Trindade hace hincapié en que la cuestión de los poderes o facultades inherentes se ha planteado reiteradamente ante los tribunales internacionales (parágrafo 16). Se refiere a sus propias opiniones separadas y disidentes anteriores (parágrafos 16-18, 20-22 y 24-26) tanto en la CIJ como en la Corte Interamericana de Derechos Humanos (Corte IDH) en sus distintos aspectos, y señala las facultades inherentes y más allá del consentimiento del Estado: "A falta de una disposición expresa al respecto, los tribunales internacionales tienen derecho a ejercer sus facultades inherentes para asegurar la buena administración de la justicia" (parágrafo 19).

6. Esto le lleva a la cuestión de la interpretación teleológica, según el principio del effet utile, o ut res magis valeat quam pereat. A su entender, la interpretación teleológica, a la que apoya, "abarca no sólo el derecho material o sustantivo (por ejemplo, los derechos reivindicados y protegidos), sino también las cuestiones jurisdiccionales y el derecho procesal" (parágrafo 22), como lo demuestra la jurisprudencia pertinente tanto del Tribunal Europeo de Derechos Humanos (TEDH) como la de la Corte Interamericana de Derechos Humanos (parágrafos 23 y 26).

7. Tras revelar las dificultades del voluntarismo estatal en la solución judicial de las controversias internacionales, subrayó que, en su opinión,

a diferencia de lo que la CIJ suele suponer, el consentimiento de los Estados no es en absoluto un 'principio fundamental', ni siquiera es un 'principio'; es como máximo una regla (que contiene una prerrogativa o una concesión a los Estados) como el acto inicial de comprometer una obligación internacional. Definitivamente no es un elemento de 
interpretación de los tratados. Una vez realizado ese acto inicial, no condiciona el ejercicio de la jurisdicción obligatoria de un tribunal, que preexistía y continúa operando sin ser afectada por éste (parágrafo 27).

8. Pasando a otro aspecto, a nivel epistemológico, el juez Cançado Trindade afirma entonces que el entendido, que él sostiene, de que la recta ratio se encuentra por encima de la voluntas, y la conciencia humana por encima de la 'voluntad', está en línea con el pensamiento jusnaturalista, volviendo a la lecciones de los 'padres fundadores' del derecho de las naciones (a partir de las lecciones del siglo XVI de Francisco de Vitoria), basadas en una lexpraeceptiva, aprehendida por la razón humana, y ciertamente no derivada de la 'voluntad' de sujetos de derecho (Estados y otros). Y añade:

El camino estaba así pavimentado para la aprehensión de un verdadero jus necessarium, trascendiendo las limitaciones del jus voluntarium. Las lecciones de los 'padres fundadores' de nuestra disciplina son perennes, están dotadas de una impresionante actualidad. [...].

Por el contrario, la concepción voluntarista, obsesionada con el consentimiento o la 'voluntad' del Estado, ha demostrado defectos, no sólo en el ámbito del derecho, sino también en los dominios de otras ramas del conocimiento humano. El apego al poder, ajeno a los valores, no conduce a ninguna parte. En cuanto al derecho internacional, si — como argumentan los positivistas voluntaristas - es por la 'voluntad' de los Estados que se crean obligaciones, es también por su 'voluntad' que se violan, y uno termina girando en círculos viciosos que No pueden explicar la naturaleza de las obligaciones internacionales (parágrafos 28 a 29).

9. El juez Cançado Trindade revisa la doctrina jurídica internacional en esta línea de pensamiento (parágrafos 30-37), que es suya, así como sus opiniones separadas y disidentes dentro de la CIJ a este efecto (parágrafos 38-40), y luego agrega:

Parece lamentable que, aún en nuestros días, la obsesión con la dependencia del consentimiento estatal permanezca presente en la práctica legal y la adjudicación internacional, aparentemente por la fuerza de la inercia mental. En mi opinión, es difícil evitar la impresión de que, si uno sigue dando un lugar privilegiado al voluntarismo estatal, no vamos a ir más allá de la prehistoria de la solución judicial de las controversias 
entre Estados, en los que todavía vivimos. Permítaseme aquí reiterar que la recta ratio está por encima de voluntas, y la conciencia humana está por encima de la 'voluntad' (parágrafo 41).

10. Pasando a la cuestión de la competencia de la competencia (Kompetenz Kompetenz) más allá del consentimiento estatal, el juez Cançado Trindade señaló que los tribunales internacionales de derechos humanos (como la Corte IDH y el TEDH), en particular, cuya jurisprudencia ha sido invocada por las partes contendientes en el curso del procedimiento ante la CIJ en el presente caso de presuntas violaciones de los derechos soberanos y los espacios marítimos en el mar Caribe, han tenido éxito,

liberándose de las cadenas del consentimiento estatal y, por lo tanto, han logrado preservar la integridad de sus respectivas jurisdicciones. Han perseguido sistemáticamente una interpretación teleológica, han afirmado su competencia de la competencia y han ejercido sus poderes inherentes.

[...] Entendieron acertadamente que su competencia de la facultad, y sus facultades inherentes, no están limitadas por el consentimiento del Estado; por el contrario, simplemente no serían capaces de impartir justicia.

Estos dos tribunales internacionales se opusieron a la postura voluntarista e insistieron en su competencia de la competencia como guardianes y amos de sus respectivas jurisdicciones. El TEDH y la Corte IDH contribuyeron a la primacía de las consideraciones de orden público sobre el voluntarismo subjetivo de los Estados. [...] En suma, por tomar tal posición de principio, la Corte IDH y el TEDH concluyeron con razón que la conciencia está por encima de la voluntad (parágrafos 43-45).

11. En cuanto a los tribunales penales internacionales, el Tribunal Penal Internacional para la ex-Yugoslavia (TPIY) también se basó en su propia competencia de la competencia (parágrafos 46 a 47). Por otra parte, los tribunales internacionales han hecho uso de sus facultades o facultades inherentes en situaciones distintas (párrafos 48 a 55), por ejemplo, para llenar las lagunas de su interna corporis (parágrafo 56). Parece, en efecto, ser un reconocimiento general hoy en día de la multiplicidad de situaciones posibles del uso de facultades inherentes por los tribunales internacionales, teniendo en cuenta en particular las funciones propias de cada tribunal internacional. En suma, 
los tribunales internacionales contemporáneos han recurrido a las facultades inherentes que les parecen necesarias para el adecuado ejercicio de sus respectivas funciones judiciales. Ellos han demostrado su preparación para hacer uso de sus facultades inherentes (para decidir sobre asuntos de jurisdicción, o manejo de evidencia, o bien méritos y reparaciones), y no han hecho uso de ellos, en situaciones distintas, para asegurar una adecuada y sana administración de justicia (parágrafo 58).

12. Según la opinión del juez Cançado Trindade, la preocupación de los tribunales internacionales es "dotar a sus respectivas funciones judiciales de las facultades inherentes necesarias para asegurar la correcta y sana administración de la justicia" (parágrafos 59 a 60). Es su entendimiento que "su tarea va más allá de la solución pacífica de las controversias, ya que también dicen lo que es la ley (juris dictio)" (parágrafos 61-62). Han ido más allá de la justicia transaccional tradicional. Hay apoyo a su concepción amplia, que dice que la ley es juris dictio, contribuyendo así también al desarrollo progresivo del derecho internacional, por ejemplo, en la jurisprudencia pertinente de los tribunales internacionales de derechos humanos y de los tribunales penales internacionales (parágrafo 63). También está implícito en la noción de "juicios experimentales/arrêts pilotes" en la obra específicamente del TEDH (parágrafo 66).

13. En cuanto al aspecto restante de las facultades inherentes y la supervisión del cumplimiento de las sentencias (una cuestión planteada por las dos partes contendientes, por motivos distintos ante la CIJ), el juez Cançado Trindade considera que el hecho de que un tribunal internacional pueda contar con la asistencia de otro órgano de supervisión para buscar el cumplimiento de sus propias sentencias y decisiones no significa en absoluto que, una vez dictada su sentencia o decisión, pueda permanecer indiferente en cuanto a su cumplimiento (parágrafo 67).

14. Por ejemplo, el hecho de que el párrafo 2 del artículo 94 de la Carta de las Naciones Unidas confíe al Consejo de Seguridad la ejecución de las sentencias y decisiones de la $\mathrm{CIJ}$ "no significa que su cumplimiento deje de ser una preocupación de la Corte. De ningún modo. Por otra parte, en la práctica, el Consejo de Seguridad muy rara vez ha hecho nada en este sentido”. Es importante evitar la violación adicional del incumplimiento; esto "sigue siendo una preocupación de la CIJ, así como de todos los demás tribunales internacionales" (parágrafo 68).

15. En el caso de la CIJ, en particular, se ha asumido erróneamente que no incumbe a la Corte garantizar el cumplimiento de sus propias 
sentencias y decisiones. El párrafo 2 del artículo 94 de la Carta de las $\mathrm{Na-}$ ciones Unidas no confiere al Consejo de Seguridad la facultad exclusiva de garantizar ese cumplimiento y una mirada más atenta a algunas disposiciones del Estatuto ${ }^{1}$ muestra que "la Corte tiene derecho a ocuparse del cumplimiento de sus propias sentencias y decisiones" (parágrafo 69). El juez Cançado Trindade considera que lo que se debe criticar "no es la creación de leyes judiciales (como suele decirse sin reflexión), sino más bien la inactividad judicial o el absentismo, particularmente en lo que se refiere al cumplimiento de sentencias y decisiones" (parágrafo 70).

16. A continuación, señala que, por su parte, el TEDH cuenta con la asistencia del Comité de Ministros, y la Corte IDH ha recurrido a audiencias posteriores a la celebración de un juicio (parágrafo 71). Las competencias del Comité de Ministros para supervisar la ejecución de las sentencias del TEDH tampoco son exclusivas; El tribunal puede ocuparse de él, como lo ha reconocido expresamente el propio TEDH. En suma, en su entendimiento, "ningún tribunal internacional puede permanecer indiferente ante el incumplimiento de sus propias sentencias. Las facultades inherentes a los tribunales internacionales se extienden también a este ámbito, a fin de garantizar el debido cumplimiento de sus resoluciones y decisiones" (parágrafo 72). Y añade:

Al hacerlo, los tribunales internacionales están preservando la integridad de sus respectivas jurisdicciones. Sorprendentemente, la doctrina jurídica internacional no ha dedicado suficiente atención a esta cuestión en particular. Esto es lamentable, ya que el cumplimiento de las sentencias y decisiones de los tribunales internacionales es un factor clave para fomentar el estado de derecho en la comunidad internacional. A partir de 2006, el tema del "Estado de derecho a nivel nacional e internacional" ha permanecido presente en el orden del día de la Asamblea General de las Naciones Unidas ${ }^{2}$ y ha ido llamando la atención cada vez mayor de los Estados miembros año tras año.

[...] El camino hacia la justicia es largo y no se ha logrado mucho hasta la fecha en cuanto a la adecuada conceptualización de la supervisión

Artículos 41, 57, 60 y 61(3).

2 Resoluciones de la Asamblea General 61/39, del 18.12.2006; 62/70, del 06.12.2007; 63/128, del 11.12.2008; 64/116, del 16.12.2009; 65/32, del 06.12.2010; 66/102, del 09.12.2011; 67/97, del 14.12.2012; 68/116, del 16.12.2013; 69/123, del 10.12.2014; y 70/118, del 14.12.2015. 
del cumplimiento de las sentencias y decisiones de los tribunales internacionales. En cambio, la fuerza de la inercia mental ha persistido a lo largo de décadas. Es hora de superar este absentismo y pasividad. La supervisión de este cumplimiento es, después de todo, una cuestión jurisdiccional. Un tribunal internacional no puede permanecer indiferente en cuanto al cumplimiento de sus propias sentencias y decisiones (parágrafos 73 y 75 ).

17. Por último, pero no por ello menos importante, en su breve epílogo, el juez Cançado Trindade señala que el trámite de la Corte en el presente caso de "la cuestión planteada por la cuarta excepción preliminar de Colombia no refleja la riqueza del proceso en el caso de la especie, y de los argumentos presentados ante la CIJ (en las fases escrita y oral) por Nicaragua y Colombia" (parágrafo 76).

18. A su juicio,

sus observaciones han sido plenamente tenidas en cuenta expresamente en la presente sentencia, aunque también desestimen la cuarta excepción preliminar al final. Después de todo, las comunicaciones de las partes en el presente caso de Presuntas violaciones de los derechos soberanos y los espacios marítimos en el mar Caribe plantean una importante cuestión recurrentemente planteada ante la Corte, que sigue exigiendo nuestra reflexión para intentar mejorar la realización de justicia a nivel internacional (parágrafo 77).

19. El hecho de que la Corte haya constatado en la presente sentencia que tiene jurisdicción en virtud del Pacto de Bogotá (desestimando la primera excepción preliminar de Colombia), a juicio de Cançado Trindade "no le impide considerar los argumentos de las partes en conflicto sobre una cuestión tan importante como sus facultades inherentes o facultés (pronunciarse sobre el supuesto incumplimiento de su sentencia de 2012)"3 (parágrafo 78). Se siente obligado a hacerlo, aunque considere que la cuarta excepción preliminar es insostenible y, por lo tanto, debe ser rechazada, en vez de haber dicho simplemente — como ha hecho la Corte, "de manera elusiva"-que "no hay sustento" para pronunciarse sobre él. ${ }^{4}$

3 Cf. parágrafos 17 y 102 de la presente sentencia.

4 Cf. parágrafos 104 y punto resolutorio 1(e) del dispositif de la presente sentencia. 
20. La consideración del uso de facultades o facultades inherentes por los tribunales internacionales contemporáneos, más allá del consentimiento estatal, ha llevado al juez Cançado Trindade, en la presente opinión separada, a poner de manifiesto su entendimiento de que "la recta ratio está por encima de la voluntas. Es necesario superar la concepción voluntarista del derecho internacional. Es necesario una mayor conciencia, de la primacía de la conciencia por encima de la 'voluntad' y de una atención constante a los valores humanos fundamentales, para asegurar el desarrollo progresivo del derecho internacional y, en última instancia, fomentar la realización de la justicia en internacional" (parágrafo 82).

\section{Declaración del juez Bhandari}

En su declaración el juez Bhandari recuerda que se ha sumado a la mayoría en relación con las primeras cuatro excepciones preliminares elevadas por Colombia, pero difiere de la mayoría en que él aceptaría la quinta excepción preliminar de Colombia y con ello rehusar que el caso presente proceda a la etapa de méritos. El juez Bandhari señala que, según la quinta objeción preliminar, la demanda de Nicaragua constituye un intento inapropiado para hacer que la Corte ejecute uno de sus fallos. Según el artículo 94(2) de la Carta de las Naciones Unidas y el artículo L del Pacto de Bogotá, es claro que el foro apropiado para que una parte agraviada busque la ejecución de una sentencia de la CIJ es el Consejo de Seguridad de las Naciones Unidas. Aunque tanto Nicaragua como Colombia han claramente enmarcado este caso como una solicitud para ejecutar la sentencia de 2012, la Corte a pesar de ello ha declarado en la presente sentencia que el verdadero carácter de la disputa involucra las alegadas violaciones de derecho internacional consuetudinario por Colombia. Aunque legalmente es correcto que le corresponde a la Corte — y no a las partes — ser quien finalmente determina la esencia de la disputa, el juez Bhandari disiente de la mayoría en cuanto a la conclusión factual de que la presente demanda de Nicaragua no busca una ejecución de la sentencia de 2012. La mayoría cita el parágrafo 79 de la presente sentencia para justificar su conclusión de que la disputa no nace directamente de la sentencia de 2012. Aun así, el parágrafo 79 y su análisis precedente tratan del análisis de la Corte de un asunto totalmente separado correspondiente en todo a otra objeción preliminar de Colombia diferente — siendo esta la existencia o no de disputa entre las partes cuando Nicaragua presentó su demanda-, asunto que no tiene lugar en esta pregunta concreta. Adicionalmente, existe abundante evidencia en el 
archivo del caso, la cual la mayoría no tuvo en cuenta de forma plena, que demostraba claramente cómo la presente demanda de Nicaragua es un intento obvio de buscar la ejecución de la sentencia de 2012.

\section{Opinión disidente del juez ad hoc Caron}

El juez Caron disiente de los hallazgos de la Corte en cuanto a la segunda y la tercera excepciones preliminares de Colombia, en tanto el razonamiento de la Corte se separa de su propia jurisprudencia y no está soportado por la evidencia presentada ante ella. Más allá de las particularidades del caso, es de gran preocupación para el juez Caron que, al encontrar que sí cuenta con jurisdicción, la Corte mediante su razonamiento afecta conceptos generales a la base de la solución pacífica de controversias.

El juez Caron recuerda que el título completo del Pacto de Bogotá es 'Tratado Americano de Soluciones Pacíficas' y observa que, aunque no exista una expresa sucesión de procedimientos en el Pacto de Bogotá, la solución pacífica dentro del marco del Pacto cuidadosamente escala del diálogo en el cual las preocupaciones de cada Estado son manifestadas al otro hacia los distintos medios por los cuales la solución puede ser negociada, y finalmente, al poder de una corte o tribunal para decidir disputas de 'naturaleza' jurídica. Un desacuerdo es más que un patrón de conducta que pueda implicar una diferencia de puntos de vista. Como el Pacto lo reconoce, la comunicación es esencial porque un desacuerdo no puede ser resuelto salvo que exista diálogo que defina lo que está en disputa. Efectivamente, salvo que una disputa en ese sentido 'exista', es difícil considerar qué es lo que será negociado.

El juez Caron disiente de la sentencia de la Corte porque fundamentalmente debilita este esquema, reduciendo la complejidad del esquema para la solución de controversias establecido en el Pacto de Bogotá a la simple aceptación de la jurisdicción de la Corte. La sentencia, al profundamente cambiar el requerimiento de que exista una disputa, sostiene que el demandante ante la Corte no tiene que haber establecido un diálogo, ni expresado sus preocupaciones al otro Estado. Sin tal diálogo, las partes no tienen la oportunidad de definir la disputa, ajustar la disputa y - se espera- limitarla o, incluso, resolverla. Críticamente, al determinar que el demandante no tiene que haber establecido un diálogo con la otra parte, cualquier deber de negociar, en la práctica, se ve sustancialmente afectado. Las disputas internacionales son complejas y las disputas limítrofes están entre las más difíciles de resolver. El derecho da respuestas, pero 
no necesariamente las más matizadas para esas situaciones complejas. Es esencial que las cortes tengan jurisdicción para dar respuesta a una disputa cuando sea necesario o sea el deseo de las partes. Pero solo es necesario, bajo el Pacto de Bogotá, cuando la disputa entre las partes "no puede ser resuelta por negociaciones directas". Así es el lenguaje en el artículo II del Pacto que la jurisprudencia de la Corte ha considerado un prerrequisito para tener jurisdicción bajo el Pacto. Es lamentable, en la opinión del juez Caron, que la presente sentencia en su decisión sobre la segunda y tercera excepción preliminar formalmente afirme, pero sustancialmente niegue, el requisito de que exista una disputa entre las partes y la obligación de entablar negociaciones.

Más específicamente, en cuanto a la segunda excepción preliminar, el juez Caron, aplicando la jurisprudencia previa de la Corte en cuanto al significado y existencia de la disputa, no puede ver cómo una disputa sobre el objeto invocado por Nicaragua en su demanda existía para la fecha requerida. En los procedimientos, la segunda excepción preliminar no llega al punto de argumentar que no se oponía firmemente a las posiciones de Nicaragua. La segunda excepción preliminar de Colombia sostiene un punto más fundamental, siendo este que Nicaragua nunca hizo un reclamo al que Colombia se pudiera oponer. Esta diferencia significativa no es tenida en cuenta en la sentencia. Puede ser apropiado para la Corte inferir la oposición a un reclamo, pero no es, según el juez Caron, apropiado inferir la producción y afirmación de tal reclamo.

El juez Caron concluye de su revisión completa de los elementos fácticos que, antes de la presentación de la demanda, Nicaragua no había hecho ninguna reclamación de que Colombia hubiera violado sus derechos soberanos o espacios marítimos o que hubiera de forma ilegal amenazado con el uso de la fuerza. En su análisis, la Corte da vuelta a su jurisprudencia sobre el requisito de la existencia de la disputa para la época en la que la demanda es presentada. En este caso, la Corte se pregunta si el demandante - Nicaragua — hizo en alguna forma una reclamación de una violación jurídica antes de la presentación de su demanda. En cambio, infiere que el demandado debía 'conocer' que el demandante efectivamente se oponía a las acciones del demandado. Según el juez Caron, este razonamiento malinterpreta la jurisprudencia de la Corte en cuanto al requisito de la existencia de la disputa. Esta decisión en la práctica señala el fin de la aplicación del requisito de la existencia de la disputa.

Más específicamente, en cuanto a la tercera objeción preliminar, el juez Caron observa que la Corte en su sentencia procede basada en la sen- 
tencia de 1988, en cuanto a la referencia de que las negociaciones directas en el artículo II del Pacto "constituyen una condición precedente al recurso de los procedimientos de solución pacífica en todos los casos" - Acciones fronterizas y transfronterizas (Nicaragua c. Honduras), sentencia de jurisdicción y admisibilidad, CIJ Reportes 1988, p. 94, para. 62- En tal proceder la Corte sostiene que el test para determinar si una solución no es posible es "si la evidencia provista demuestra que, a la fecha de la presentación de la demanda de Nicaragua, ninguna de las partes podía plausiblemente mantener que la disputa entre ellos podía ser resuelta por negociaciones directas mediante los canales diplomáticos habituales".

El juez Caron disiente de la Corte indicando que "ninguna evidencia presentada a la Corte indica que, a la fecha de la presentación de la demanda de Nicaragua, las partes hubieran contemplado o estuvieran en la posición, de sostener negociaciones para resolver la disputa concerniente a las presuntas violaciones por Colombia de los derechos de Nicaragua en sus espacios marítimos" y en los argumentos que rechazan la tercera excepción preliminar de Colombia. Para el juez Caron, la conclusión de la Corte no solo no está soportada en la evidencia, sino que es contradicha por la evidencia específica citada por la Corte.

La conclusión final del juez Caron es que la Corte, al determinar el objeto de la disputa presentada ante ella, está llamada a hacer finas distinciones. En el caso presente, el juez Caron nota que la Corte ha hecho una decisión muy delicada entre un reclamo por incumplimiento a una sentencia de la Corte y un reclamo por la violación de derechos otorgados por esa sentencia. El presente fallo, en la opinión del juez Caron, en todo caso, deja claro que la Corte no es tan prolija al distinguir cuándo una pieza de evidencia señala el incumplimiento de la sentencia de 2012 o una violación a derechos soberanos y espacios marítimos definidos en la sentencia de 2012. La facilidad con la cual ambas reclamaciones se sobreponen y la dificultad que la Corte tiene al momento de estudiar la evidencia seguramente dificultarán la tarea de la Corte en la etapa de méritos del presente caso. 